AperTO - Archivio Istituzionale Open Access dell'Università di Torino

\title{
Constitutive polyphenols in blades and veins of grapevine (Vitis vinifera L.) healthy leaves
}

\section{This is the author's manuscript}

Original Citation:

Availability:

This version is available http://hdl.handle.net/2318/1679943

since 2020-04-01T15:39:32Z

Published version:

DOI:10.1021/acs.jafc.8b03418

Terms of use:

Open Access

Anyone can freely access the full text of works made available as "Open Access". Works made available under a Creative Commons license can be used according to the terms and conditions of said license. Use of all other works requires consent of the right holder (author or publisher) if not exempted from copyright protection by the applicable law. 
CONSTITUTIVE POLYPHENOLS IN BLADES AND VEINS OF GRAPEVINE (Vitis vinifera,

L.) HEALTHY LEAVES.

Olga Kedrina-Okutan'1, Vittorino Novello ${ }^{1}$, Thomas Hoffmann², Johannes Hardersdorfer Andrea Occhipinti ${ }^{4}$, Wilfried Schwab ${ }^{2}$, and Alessandra Ferrandino ${ }^{1 *}$

${ }^{1}$ Dipartimento Scienze Agrarie, Forestali, Alimentari (DISAFA), Università degli Studi di Torino, Largo P. Braccini, 2 10095, Grugliasco (TO).

${ }^{2}$ Biotechnology of Natural Products, Technical University Munich, Liesel-Beckmann-Str. 1, 85354

Freising, Germany.

${ }^{3}$ Fruit Science, Technical University Munich, Dürnast 2, 85354 Freising, Germany.

${ }^{4}$ at present Abel Nutraceuticals S.r.l. Via P. Veronese 202, 10139, Turin (Italy) - previously Department of Life Sciences and Systems Biology, University of Turin, Innovation Centre, Via Quarello 15/A, 10135 Turin, Italy.

*corresponding author: tel.+39-011-6708755; email: alessandra.ferrandino@unito.it 


\section{ABSTRACT}

2 Despite the economic importance and the diffusion of grapevine cultivation worldwide, little is known

3 about leaf chemical composition. We characterized the phenolic composition of Nebbiolo, Barbera,

4 Pinot noir, Cabernet Sauvignon, Grenache and Shiraz (Vitis vinifera L.) healthy leaves (separating blades

5 and veins) during the season. Quantitative and qualitative differences were found between leaf sectors

6 and among genotypes. In healthy grapevine leaves, anthocyanins, dihydromyricetin-rhamnoside,

7 hexosides of dihydroquercetin and dihydrokaempferol exclusively accumulated in veins. Astilbin was

8 the only flavanonol detected in blades and the prevalent flavanonol in veins. Barbera distinguished for

9 the lowest proanthocyanidin and the highest hydroxycinnamate content; Pinot noir for the absence of acylated-anthocyanins. Nebbiolo, Pinot noir and Cabernet Sauvignon displayed high concentration of epigallocatechin gallate. Nebbiolo leaves showed the highest concentrations of flavanonols and the widest profile differentiation. Knowledge derived from the present work is a contribution to find out leaf polyphenol potential as a part of grapevine defense mechanisms and to dissect genotype-related susceptibility to pathogens; moreover, it represents a starting point for future deepening about grapevine and vineyard by-products as a source of bioactive phenolic compounds.

KEYWORDS: anthocyanins, flavonols, hydroxycinnamic acids, flavan-3-ols, flavanonols, HPLC- 


\section{INTRODUCTION}

Grapevine (Vitis vinifera L.), one of the most widely cultivated plant species worldwide, comprises 5000 to 10000 varieties $^{1}$ and it plays important role in the economy of many countries due to wine, and fresh and dry grape production. Grapevine vegetative organs (shoots, stems and leaves) are used in traditional plant-based medicine as a source of bioactive compounds. ${ }^{2,3}$ According to recent studies, grapevine leaves have beneficial effect on human health due to their anti-inflammatory, antibacterial, anticancerogenic, antiviral, antioxidant properties. ${ }^{4}$ In the Middle East and Mediterranean regions, grapevine leaves are commonly used as food both in fresh and brined forms. ${ }^{5}$

Grapevines produce large amount of secondary metabolites, including chemically heterogeneous phenolic compounds. Due to this huge diversity, each group of phenolic compounds displays various roles in grapevine biology and ecology, conferring them a key role in grapevine adaptation to the environment. Polyphenols are part of the plant-defence mechanisms relying on molecular communication among plants and pathogens, involving signals for the establishment of infection, the activation of plant disease- resistance genes, the formation of elicitors, the activation of elicitor receptors and, finally gene regulation. In many of these steps phenylalanine ammonia lyase (PAL) and the chalcone synthase genes $(\mathrm{CHs})$ are suppressed or over-expressed, resulting in the modulation of the accumulation of main classes of polyphenols. ${ }^{6}$ Accumulation of polyphenols varies among plant organs, tissues and phenological stages. Many traits of the phenolic compound biosynthesis in grapevine berries are well detailed and it is well-known that they are under genetic control, even though external abiotic or biotic factors can influence polyphenolic concentrations and, sometimes, profiles. At the berry level the wide differences in the polyphenolic composition of Vitis vinifera varieties and clones have been investigated..$^{7-9}$ Polyphenol accumulation and profiles are influenced by seasonal climatic conditions, biotic and abiotic stressors, soil and cultural practices. Nevertheless, some traits are genetically determined, thus specific quantitative and qualitative chemical patterns characterize Vitis vinifera varieties. In berries, the ratio between tri-hydroxylated and di-hydroxylated anthocyanins and the ratio 
between caftaric acid and coutaric acid are stable and they have long time been proposed as tools to classify Vitis vinifera varieties and clones. ${ }^{7-9}$ Much less is known about vegetative organ polyphenolic composition, even though specific molecules or groups of molecules could be responsible of the inner and constitutive biochemical protection of the vine against various abiotic and biotic stressors. ${ }^{10}$ Increasing knowledge about constitutive leaf polyphenols could be pivotal to explain the different level of susceptibility to pathogens displayed by Vitis vinifera genotypes. Different compositional traits and changes during the season in leaf compartments (blades and veins) can provide new insights about the interpretation of plant interaction with pathogens specifically accumulating in these two different leaf sectors. The present work investigates the polyphenolic concentration and profiles of grapevine leaves during the vegetative season to individuate characteristic chemical patterns in some Vitis vinifera varieties and to explore their constitutive accumulation as a part of grapevine defense potential mechanism. To provide new insights about concentrations, profiles and trends of main polyphenols in different leaf tissue, we analyzed blades and veins separately to spread light, in particular, on the vein constitutive polyphenols that could help to understand the different susceptibility of Vitis vinifera varieties to pathogens with vascular localization. To our knowledge, little is known about the polyphenolic characterization of Vitis vinifera leaf blades and veins analyzed separately and about their evolution during the vegetative season. Leaf polyphenols were analyzed spectrophotometrically and by targeted analytical approach using HPLC-DAD for quantitative or semi-quantitative purposes and HPLC-ESI-MS/MS for molecular identification.

\section{MATERIALS AND METHODS}

\section{Plant material}

The leaves of two major Italian varieties (Barbera - BR and Nebbiolo - NE) and of four international varieties (Pinot noir - PN, Cabernet Sauvignon - CS, Grenache - GR and Shiraz - SH) were sampled in the collection vineyard of DISAFA, University of Turin located at Grugliasco $\left(45^{\circ} 03^{`} \mathrm{~N}\right.$, $7^{\circ} 35^{\prime} \mathrm{E}$; in Piedmont, Italy), in 2015. Vine density was 4400 vines/ha (0.90 m x $\left.2.50 \mathrm{~m}\right)$, vines were 
planted in 2008, vertical shoot positioned and trained to the Guyot pruning system. The vineyard is located at $293 \mathrm{~m}$ above s.l., in a plain area. A detailed soil description is reported in Catoni et al. ${ }^{11}$ Briefly, the A horizon $\mathrm{pH}$ was 7.9 , organic $\mathrm{C}$ was $14.8 \mathrm{~g} \mathrm{~kg}^{-1}$, sand was $882 \mathrm{~g} \mathrm{~kg}^{-1}$, silt was $101 \mathrm{~g} \mathrm{~kg}^{-1}$ and clay $17 \mathrm{~g} \mathrm{~kg}^{-1}$. The vineyard was organized in randomized blocks of maximum twelve vines each. Leaf samples were collected at five different time points: $1=22^{\text {th }}$ of May (142 day of the year, DOY 142 ), $2=2^{\text {nd }}$ of July (DOY 183), $3=16^{\text {th }}$ of July (DOY 197), $4=29^{\text {th }}$ of July (DOY 210), $5=26^{\text {th }}$ of August (DOY 238) in 2015. The general meteorological parameters of the vineyard are reported in Supplementary Table 1. Three adult healthy leaves between the fourth and the seventh node of main shoots per each block were collected from the west side of the row and immediately transported to the laboratory where leaves were rinsed, dried with a paper before blades and veins separation and extraction.

\section{Dry matter content}

Leaf tissue dry matter was measured gravimetrically by drying inside an oven at $110{ }^{\circ} \mathrm{C}$ for 72 hours.

\section{Sample extraction}

Notwithstanding the well-known effects of water content on polyphenol final concentrations, we decided to work on fresh leaves, immerging blades and veins in an appropriate and specifically chosen extraction solvent (see below) soon after picking as freeze drying, including lyophilisation, can imperfectly preserve plant secondary metabolites, particularly polyphenols, as previously reviewed. ${ }^{12}$ To ascertain the most adequate extraction solvent for leaf polyphenol analyses, we extracted three biological replicates of Nebbiolo blades and veins in seven different solvents: $\mathrm{CH}_{3} \mathrm{OH} 80 \%$; $\mathrm{CH}_{3} \mathrm{OH}$ $80 \% / \mathrm{HCl} 0.1 \%$; acetone $50 \%$; acetone $50 \% / \mathrm{HCl} 0.1 \%$; phosphate-citrate buffer (pH 3.6); hydroalcoholic buffer (ethanol 12\%, pH 3.2) and hydroalcoholic buffer (ethanol 40\%, pH 3.9). This last gave the best results (see Results) thus two grams of leaf blades and two grams of leaf veins were extracted in $25 \mathrm{~mL}$ of this pH 3.9 hydroalcoholic buffer (40\% ethanol, $2 \mathrm{~g} / \mathrm{L}$ of $\mathrm{Na}_{2} \mathrm{~S}_{2} \mathrm{O}_{5}, 5 \mathrm{~g} / \mathrm{L}$ of tartaric acid, $22 \mathrm{~mL} / \mathrm{L}$ of 
$1 \mathrm{~N} \mathrm{NaOH}$ ). The samples were homogenized with an Ultraturrax dispersing machine (IKA, Staufen, Germany), centrifuged for $10 \mathrm{~min}$ at $4000 \mathrm{rpm}$. The supernatant was separated and kept in the dark. The pellet was re-suspended in $20 \mathrm{~mL}$ of the same buffer; the resuspension was macerated for 30 minutes at room temperature in the dark and then centrifuged again. The two extracts were combined and brought to a final volume of $50 \mathrm{~mL}$. Extracts were stored at $-20{ }^{\circ} \mathrm{C}$ until further analysis.

\section{Reagents and Standards}

Bovine serum albumin (BSA), sodium hydroxide, triethanolamine (TEA), and urea were purchased from Sigma-Aldrich S.r.l. (Milan, Italy). Folin-Ciocalteu reagent and tartaric acid were purchased from Merck (Darmstadt, Germany). Sodium sulfate and sodium metabisulfite were purchased from BDH Laboratory Supplies (Poole, England). Quercetin 3-O-glucoside, quercetin 3-O-glucuronide, kaempferol 3-O-glucoside, kaempferol 3-O-glucuronide, myricetin 3-O-glucoside, isorhamnetin 3-Oglucoside, malvidin 3-O-glucoside, (+)- catechin, (-)-epicatechin, (-)-epicatechin gallate, (-)epigallocatechin gallate, proanthocyanidin $B_{1}$ and proanthocyanidin $B_{2}$ were purchased from Extrasynthèse (Genay, France). Astilbin and trans-caftaric acid were purchased from Sigma-Aldrich S.r.l. (Milan, Italy); trans-fertaric acid and trans-coutaric acid were purchased from Phytolab (Vestenbergsgreuth, Germany).

\section{Spectrophotometric analyses}

Total polyphenols (TP) in grapevine leaves were measured with the Folin-Ciocalteu reagent. Absorbance was read at $760 \mathrm{~nm}$ in a UV/Vis spectrophotometer (Perkin Elmer, Lambda 25, Beaconsfield, Bucks, U.K.) and TP were expressed as grams of (+)-catechin equivalents (CE) per kg of leaf blade/vein fresh weight (FW).

Measurement of total proanthocyanidins (PA) in leaves was performed spectrophotometrically by the improved protein precipitation method of Harbertson et al. ${ }^{13}$ Briefly, $1 \mathrm{~mL}$ of BSA protein solution was added to $500 \mu \mathrm{L}$ of sample extract for PA-protein precipitation. Buffer containing $5 \%$ of triethanol amine (TEA, v/v) and 5\% of urea (w/v) was used for dissolving PA-protein pellet after 
centrifugation and to support the colorimetric reaction with ferric chloride. Background and final absorbances were measured at $510 \mathrm{~nm}$ and sample absorbance was determined by subtracting the background absorbance from the final reading. The results were expressed as grams of (+)-catechin equivalents (CE) per $\mathrm{kg}$ of leaf blades/veins FW.

\section{Analyses of anthocyanins}

\section{Sample preparation}

Anthocyanin leaf extracts were retained on a Sep-Pak C18 silica-based bonded phase cartridge (Waters Corp., WAT051910, Milford, USA) and eluted with methanol. The methanolic solution was evaporated to dryness in a rotary evaporator (Laborata 4000, Heidolph Instruments GmbH \& Co. KG, Schwabach, Germany). The extracts were re-suspended with solvent B and passed through $0.20 \mu \mathrm{m}$ membrane filter GHP Acrodisc® (PALL Italia, Buccinasco, Milano, Italy).

\section{Qualitative analyses of anthocyanins by HPLC-DAD-ESI-MS/MS}

Samples were analyzed by liquid chromatography (1200 HPLC, Agilent Technologies, USA) equipped with a Luna reverse phase C-18 column $(3.00 \mu \mathrm{m}, 150 \mathrm{~mm} \times 3.0 \mathrm{~mm}$, Phenomenex, USA). The instrument was equipped with a binary solvent pump with the following solvents: (A) MilliQ water (Millipore, U.S.A.) with 10\% v/v of formic acid and (B), methanol/water/formic acid 50/40/10 v/v. The chromatographic separation was carried out at a constant flow rate $\left(200 \mu \mathrm{min}^{-1}\right)$ and to a stepwise gradient: from $15 \%$ to $45 \%$ of B in $15 \mathrm{~min}$, to $70 \%$ of B at $35 \mathrm{~min}$, to $90 \%$ of B at $45 \mathrm{~min}$, then $99 \%$ of $\mathrm{B}$ at $55 \mathrm{~min}$, hold for $4 \mathrm{~min}$. The initial mobile phase was re-established for $11 \mathrm{~min}$ before the next injection. DAD detector was set at $520 \mathrm{~nm}$. The mass spectrometry analyses were performed with a 6330 Series Ion Trap LC-MS System (Agilent Technologies, U.S.A.) equipped with an electrospray ionization source (ESI) operating in positive mode. Qualitative analyses were performed in scan mode $\left(100-850 \mathrm{~m} / \mathrm{z}\right.$ ) and $\mathrm{N}_{2}$ dry gas temperature was set at $325^{\circ} \mathrm{C}$. Mass spectra were processed and analyzed by the DataAnalysis for 6330 Series Ion Trap LC/MS 4.0 software (Bruker Daltonik, Bremen, Germany). 
Identification of spectra was done by analysis of fragmentation pattern and by comparison with literature data.

Quantitative analyses of anthocyanins by HPLC-DAD

HPLC-DAD analysis was carried out by an Agilent 1200 Series system (Agilent, Waldbronn, Germany), equipped with a DAD detector (G1316A). Twenty $\mu \mathrm{L}$ of samples were injected on a reversephase column Purospher® STAR RP-18 endcapped (5 $\mu \mathrm{m})$ packed into LiChroCART 250-4 HPLCCartridge $(25 \times 0.4 \mathrm{~cm}$ ID; Merck KGaA, Germany) with a guard column LiChroCART $4-4$ of the same packing material. Solvent A was $10 \%$ of formic acid and solvent B was water/methanol/formic acid (40:50:10, v/v/v), the flow rate was $1 \mathrm{~mL} / \mathrm{min}$ with a gradient from $28 \%$ to $72 \%$ of $\mathrm{B}$ in 63 minutes. Individual anthocyanins were detected at $520 \mathrm{~nm}$. Results were expressed as milligrams of malvidin 3$O$-glucoside chloride equivalent per kg of leaf blade/vein fresh weight.

\section{Analyses of individual phenolic compounds}

154

155

156

157

\section{Sample preparation}

Leaf extracts were diluted with $1 \mathrm{M}$ phosphoric acid (1.1 fold) and filtered $(0.20 \mu \mathrm{m})$ into the vials. $^{14}$

\section{Qualitative analyses phenolic compounds by HPLC-DAD-ESI-MS/MS}

A Bruker Daltonics esquire 3000 plus ion trap spectrometer (Bruker Daltonics, HB, Germany) equipped with an Agilent 1100 HPLC-DAD system (Agilent Tech. Inc., CA, USA) was used for individual phenolic compound identification. Component separation was done with column Luna C-18 150 x 2 mm (Phenomex Aschaffenburg, Germany). For mobile phase solvent A was water/0.1\% formic acid and solvent B was methanol/0.1\% formic acid; gradient program was as follows: 0-30 min 0-50\% B, 30-35 min $50-100 \%$ B, 35-50 min $100 \%$ B, $50-55 \min 100 \%$ B, $55-65$ min $0 \%$ with a flow rate 0.2 $\mathrm{mL} / \mathrm{min}$. The phenolic compounds were detected at 280, 320 and $360 \mathrm{~nm}$ and injection volume was 5 $\mu \mathrm{L}$. The MS detector operated in positive and negative mode, ionization voltage of the capillary was $4000 \mathrm{~V}$, and the end plate was set to $-500 \mathrm{~V}$. The drying gas $\left(\mathrm{N}_{2}\right)$ temperature was set at $330{ }^{\circ} \mathrm{C}$ with a 
flow rate of $9 \mathrm{~L} / \mathrm{min}$ and full scan mode was between $\mathrm{m} / \mathrm{z} 100$ to 800 with a scan resolution of 13,000 $\mathrm{m} / \mathrm{z} / \mathrm{s}$ until the ICC target reached either 20,000 or $200 \mathrm{~ms}$. Tandem MS was carried out using helium as the collision gas $\left(4.21 \times 10^{-6}\right.$ mbar $)$ with $1 \mathrm{~V}$ collision voltage. Metabolite identification was based on mass spectra, product ion spectra, retention time and by comparing mass spectra with those of pure reference material. Previously published data from literature were used as reference for metabolite identification, as well.

\section{Quantitative analysis of phenolic compounds by HPLC-DAD}

Individual phenolic compounds of leaf extracts were separated by a reverse-phase column Licrosphere 100 RP-18 (5 $\mu$ m particle size $)$ packed with LiChroCART 250-4 (25 × $0.4 \mathrm{~cm}$ ID) HPLCCartridge (Merck KGaA, Germany) with a guard column (LiChroCART 4-4); the column was thermostated at $25{ }^{\circ} \mathrm{C}$. Solvent A was phosphoric acid $10^{-3} \mathrm{M}$ and solvent B was pure methanol. Chromatographic condition was established according to previously published methods by Di Stefano and Cravero ${ }^{14}$ and by Ferrandino and Guidoni ${ }^{8}$ with some modifications. Chromatograms were acquired at $280 \mathrm{~nm}, 320 \mathrm{~nm}$ and $360 \mathrm{~nm}$ simultaneously and run time was 50 minutes. Compounds were identified based on spectrum correspondence with authentic standards and quantified by the external standard method through calibration curves.

\section{Statistical analysis}

All data were analysed by SPSS 32.0 software program version 24.0 for Windows (SPSS Inc., Chicago, USA). Analysis of variance was performed by one-way ANOVA and followed by Tukey-b post-hoc test at $\mathrm{P} \leq 0.05$. All measurements were performed in triplicate and results were expressed as means \pm standard errors (SE). Heatmaps were generated by Rstudio software version 1.0.44, using the ggplot2 and Complex Heatmap R packages. The compounds used for heatmap realization were those quantified by HPLC-DAD. For each individual compound concentration, Z-scores were calculated by subtracting to each average value (variety and date) the general average of the entire population divided by the standard deviation. 


\section{RESULTS}

We analyzed polyphenol accumulation in leaves of six Vitis vinifera varieties during the vegetative season expressing data on the basis of fresh weight to limit some negative effects of freezedrying and lyophilisation on polyphenols. However, dry weight measures allowed highlighting differences in water content between leaf blades and veins over the season. It clearly emerged that the average dry matter content in veins was $10 \%$ lower with respect to that of blades for all the tested varieties; the range of variation among varieties at the same date of sampling was not higher than $6 \%$ in blades and $4 \%$ in veins, resulting in no significant differences at two dates out of three (Table 1).

Before sample preparation, several solid-liquid extractions were performed to assess the best solvent to be used for polyphenol leaf extraction, knowing that different solvents can specifically favor the extraction of specific group of molecules and that increasing content of ethanol favoured polyphenolic extraction from grape seeds. ${ }^{15} \mathrm{We}$ tried seven different solvents, evaluating their efficiency by measuring total polyphenols (TP) and total flavonoids (TF) in blades and veins, separately. Although hydroalcoholic buffer with $12 \%$ ethanol (one of the most largely used solvent in berry polyphenol measurements) allowed to measure slightly higher TP in blades, the hydroalcoholic buffer with $40 \%$ ethanol was the optimal solvent for both tissues (Table 2). Moreover, because of the known significant influence of solvent to sample volume ratio (SSR) onto polyphenol extraction yield, ${ }^{16}$ we tested different SSR and finally we adopted the SSR 25:1 for both tissues.

\section{Total Polyphenols (TP) and Total Proanthocyanidins (PA)}

The concentration of TP in grapevine blades varied from 30.1 to $50.7 \mathrm{~g} \mathrm{CE} / \mathrm{kg}$, in line with previously published data on whole leaves. ${ }^{17,18}$ In Barbera leaf blades, TP concentration increased during the vegetative season; in Shiraz at the last sampling TP concentration was higher respect to that at the first sampling (Fig. 1A). Grenache showed opposite trend as TP concentration slightly decreased, similarly to what was observed by Rusjan et al. ${ }^{17}$ in Chardonnay healthy leaves. Cabernet Sauvignon, Nebbiolo and Pinot noir showed an identical TP accumulation trend during the season, displaying a peak 
of maximum concentration at DOY 183. The concentration of TP in grapevine veins ranged from 14.8 $\mathrm{g} \mathrm{CE} / \mathrm{kg}$ to $24.6 \mathrm{~g} / \mathrm{kg}$ of fresh weight, which was twice less than in blades. Considering the dilution effect due to the higher water amount displayed in veins with respect to blades, differences between the two tissues were slightly less evident, but they were still high. In leaf veins, differently from leaf blades, no major differences were found among varieties, nor in concentrations or in trends.

In blades total proanthocyanidins (PA) increased during the season in all the examined varieties without any exception (Fig. 1C). Pinot noir and, particularly, Barbera accumulated lower amounts of PA with respect to the other biotypes. The concentration of PA in veins (Fig. 1D) was twice lower than in blades and similarly to TP results no major differences were found among the six varieties over the studied period. However, also in veins and notably at the beginning of the vegetative season, Barbera displayed a reduced PA concentration. Differences between the two Italian genotypes, Nebbiolo and Barbera were quite evident as to this parameter (Figure 1C, 1D).

\section{Identification, Quantification and Seasonal Accumulation of Anthocyanins in Grapevine Leaves}

In the present study, analysis of anthocyanins demonstrated that in healthy grapevine blades, anthocyanins were absent and their concentration was very low in veins (Fig. 2A, Supplementary Table 6). Available data on anthocyanin accumulation and profiles in healthy leaves are scarce, however the absence or low concentration of anthocyanins in healthy leaves was previously assessed in grapevine. ${ }^{19,20}$ In veins, the highest concentration of anthocyanins was detected in Cabernet Sauvignon at DOY 210 (end of July) (Fig. 2A). Nebbiolo, Barbera and Shiraz anthocyanin accumulation trend was similar: from DOY 142 to 183 (May to mid-July) the concentration increased, afterwards it declined slightly. Instead, in Pinot noir and Grenache the anthocyanin concentration increased slightly during the vegetative season, with Grenache displaying particularly low concentrations. In our study, eight anthocyanins were identified by HPLC-DAD-ESI-MS/MS in grapevine veins (Fig. 3; Table 3). Malvidin 3-O-(6-p-coumaroyl)-glucoside was the prevalent anthocyanin in healthy leaf veins (accounting for 50\% over total concentration) in all varieties with the only exception of Pinot noir (Fig. 2B), where the 
prevalent anthocyanin was malvidin-3-O-glucoside. (Fig. 2B). In Nebbiolo veins malvidin 3-Oglucoside, malvidin 3-O-(6-p-coumaroyl)-glucoside, malvidin 3-O-(6-p-caffeoyl)-glucoside and peonidin 3-O-(6-p-coumaroyl) glucoside were detected. Malvidin and its derivatives accounted for 60$70 \%$ of total anthocyanins. Barbera leaf veins showed the most complex profile with seven anthocyanins: the four detected in Nebbiolo, and, additionally petunidin 3-O-(p-coumaroyl)-glucoside in all samplings, cyanidin and delphinidin $p$-coumaroyl glucosides, in the first two samplings. Cabernet Sauvignon anthocyanin profile was similar to that of Nebbiolo with the exception of one acylated anthocyanin, whose structure remained unknown (Table 3). The concentration of anthocyanins in veins of Shiraz and Grenache was particularly low (Supplementary Table 6) and these two varieties displayed the simplest profiles (Fig. 2).

Identification, Quantification and Seasonal Accumulation of Non-Anthocyanin Phenolics in

\section{Grapevine Leaves}

Twenty-four phenolic compounds were identified in veins and twenty in blades (Table 4; Supplementary Fig. 1). The analysed phenolic compounds belonged to flavonols, hydroxycinnamic acids, flavan-3-ols, proanthocyanidins, dihydroxybenzoic acid (exclusively protocatechuic acidglucoside) and flavanonols.

\section{Flavonols}

Flavonol glycosides were quantitatively the most abundant phenolic compounds in leaves. The total flavonol glycoside content ranged from 2596.7 to $5530.9 \mathrm{mg} / \mathrm{kg}$ in blades (Fig. 4A, Supplementary Table 3A) and from 852.4 to $1607.4 \mathrm{mg} / \mathrm{kg}$ in veins where the trend of flavonol concentration was similar among biotypes, even though Barbera showed slightly higher concentrations, particularly at the first two sampling dates (Fig. 4B, Supplementary Table 3B). In Barbera leaf blades at DOY 210 (end of July) the highest concentration of total flavonols was measured and, except for Cabernet Sauvignon, which displayed an increasing trend, in the other varieties flavonols were stable or tended to slight decrease during the season. Oppositely, in Grenache, Pinot noir and Shiraz, considering that no significant 
variation of dry matter was detected during the entire season, this reduction in flavonol concentration could be ascribed to degradation tied to the beginning of senescence, being known that these varieties display a shorter vegetative cycle with respect to Nebbiolo and Barbera (Fig. 4A). In Vitis vinifera blades and veins, flavonol glycoside qualitative composition was similar (Fig. 4C, 4D). Six flavonols were identified and quantified: myricetin 3-O-glucoside, myricetin 3-O-glucuronide, quercetin 3-Oglucoside, quercetin 3-O-glucuronide, kaempferol 3-O-glucoside and kaempferol 3-O-glucuronide (Table 4). Additionally, based on mass spectra, a quercetin-pentoside was tentatively identified in Nebbiolo and Grenache veins: it showed a molecular ion $[\mathrm{M}]^{-}$at $\mathrm{m} / \mathrm{z} 433$ and gave a product ion at 301 in $\mathrm{MS}^{2}$, which indicated that this compound is a quercetin derivative. Quercetin 3-O-glucuronide was the main component followed by quercetin 3-O-glucoside; together, they accounted for up to $94 \%$ of all flavonols (Fig. 4). During the vegetative season, the flavonol profile changed due to the percentage increase of quercetin 3-O-glucoside respect to quercetin 3-O-glucuronide over flavonol total concentration.

Hydroxycinnamic acids

Hydroxycinnamic acids (HCA) were the most abundant non-flavonoid phenolics in Vitis vinifera leaves. Amounts ranged from 1.3 to $4.1 \mathrm{~g} \mathrm{~kg}^{-1}$ in blades (Fig. 5A, Supplementary Table 2A) and from 0.8 to $1.8 \mathrm{~g} \mathrm{~kg}^{-1}$ in veins (Fig. 5B, Supplementary Table 2B). Barbera leaves were able to accumulate the highest concentration of HCA compared to the other varieties. Generally, a decreasing trend of HCA concentration was detected during the vegetative period, particularly in blades. The prevalent HCA was trans-caftaric acid (77-89\%), followed by trans-coutaric acid, cis-caftaric acid, cis-coutaric acid and trace amounts of trans-fertaric acid (Fig. 5C, 5D; Table 4). Moreover, in Cabernet Sauvignon veins and blades a caffeoyl hexoside was tentatively identified: it showed maximum absorbance at $325 \mathrm{~nm}$ and a

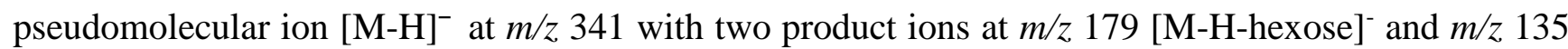
$\left[\mathrm{M}-\mathrm{H}-\text { hexose- } \mathrm{CO}_{2}\right]^{-}$in $\mathrm{MS}^{2}$, consistent with the data of a metabolite found by Chen et al. ${ }^{21}$ in Taraxacum formosanum. 
Protocatechuic acid-glucoside

Although present in small amount in leaves protocatechuic acid-glucoside was detected in both blades and veins of all the analysed varieties (Table 4). Its characteristic mass spectra showed a pseudomolecular ion $[\mathrm{M}-\mathrm{H}]^{-}$at $\mathrm{m} / z, 315$ and a product ion at $\mathrm{m} / z, 153$ [M-H-glucose] $]^{-}$The tentative identification was in accordance with previously reported $\mathrm{MS}^{2}$ profiles of protocatechuic acid-glucoside in grapes. ${ }^{22}$

\section{Flavan-3-ols}

The concentration of flavan-3-ols in leaf blades was quite stable or decreased during the examined period with the only exception of Shiraz (Fig. 6A). In Grenache an important increase of flavan-3-ol concentration characterized the period between the first two pickings (Fig. 6B). The concentrations of flavan-3-ols ranged from 177.8 to $486.3 \mathrm{mg} \mathrm{kg}^{-1}$ in blades and from 153.7 to $416.7 \mathrm{mg}$ $\mathrm{kg}^{-1}$ in veins. Differently from the other classes of compounds whose concentrations where two/three times higher in blades than in veins, the concentration of flavan-3-ols was similar in the two tissues. However, considering the dilution effect due to the vein higher water content with respect to blades, it emerges that flavan-3-ols are more concentrated in veins than in blades. In leaf veins of Cabernet Sauvignon, Shiraz and Pinot noir, flavan-3-ol concentration increased until DOY 197/210 (middle/end July) and then it decreased. In Nebbiolo, Barbera, Grenache, from DOY 142 to 183 (end of May until beginning of July) there was a significant increase of flavan-3-ol concentration, followed by a decreasing trend.

The main flavan-3-ol found in leaves was (+)-catechin, representing up to $75 \%$ of total flavan3-ols (Fig. 6C, 6D) which is consistent with Topalovic et al. ${ }^{23}$ Besides, also (-)-epicatechin was accumulated in important concentrations in leaf blades, particularly in Barbera where it accounted for 34.5 up to $52.4 \%$ of the total flavan-3-ols. Generally, in blades the concentration of (+)-catechin decreased during the examined period, which implied a profile change characterized by the reduction of (+)-catechin incidence and a general increase of that of (-)-epicatechin (except in Pinot noir) (Fig. 6A; 
Supplementary Table 4A, 4B). (-)-Epigallocatechin gallate and low amount of (-)-epicatechin gallate were detected in Vitis vinifera blades and veins. (-)-Epigallocatechin gallate relative abundance ranged from $2.6 \%$ to $18.8 \%$ in blades and from $9.8 \%$ to $30.8 \%$ in veins, in lines with data from Peng et al. ${ }^{24}$ Particularly high percentages of (-)-epigallocatechin were detected in Barbera blades (Fig. 6C) and in Nebbiolo, Pinot noir and Cabernet Sauvignon veins (Fig. 6D). Pinot noir and Cabernet Sauvignon did not show any capability to accumulate (-)-epicatechin gallate (except in Cabernet Sauvignon veins at three sampling dates).

Additionally, by LC-ESI-MS/MS proanthocyanidin dimers were tentatively identified. Three (epi)-gallocatechin-(epi)catechin isomers in blades and two isomers in veins with pseudomolecular ion $[\mathrm{M}-\mathrm{H}]^{-}$at $\mathrm{m} / \mathrm{z}, 593$ and three product ions at $\mathrm{m} / \mathrm{z}, 425,407,289$ in $\mathrm{MS}^{2}$ and two B-type procyanidins (Table 4), possibly identified as $\mathrm{B}_{1}$ and $\mathrm{B}_{3}$. The identification is supported by previously published identification of the dimeric flavan-3-ols compounds in grapevine leaves ${ }^{23}$ and berries. ${ }^{25}$

\section{Flavanonols}

During the examined period, the concentration of flavanonols in leaves was stable or slightly increased. In Pinot noir and Nebbiolo flavanonol concentration was much higher in veins than in blades (Fig. 8A, 8B). In Nebbiolo veins, flavanonol concentration was the highest, ranging from 139.3 to 251.9 $\mathrm{mg} \mathrm{kg}^{-1}$ during all the examined period compared to the other varieties and it was up to 50 times higher in veins respect to blades. Taking into account the average higher water content of veins compared to blades, the higher content of flavanonol in veins was even more remarkable. Oppositely, in Grenache no major differences were found in the flavanonol concentration of the two leaf tissues. Leaf flavanonols were a group of four glycosides, sometimes reported in grapes and wines. ${ }^{26,27}$ Based on their characteristic UV maximum absorbance at $290 \mathrm{~nm}$ and mass spectra, they were identified as dihydroquercetin-hexoside (taxifolin-hexoside), dihydroquercetin-rhamnoside (astilbin), dihydrokaempferol-hexoside and dihydromyricetin-rhamnoside (Table 4, Fig. 7). Dihydroquercetinhexoside was identified by it pseudomolecular ion $[\mathrm{M}-\mathrm{H}]^{-}$at $\mathrm{m} / \mathrm{z} 465$; product ions at $\mathrm{m} / \mathrm{z} 303$ [M-H- 
hexose; dihydroquercetin $]^{-}, 285$ [M-H-hexose- $\left.\mathrm{H}_{2} \mathrm{O}\right]^{-}, 151\left(\left[{ }^{1,3} \mathrm{~A}_{0}\right]^{-}\right.$; retro Diels-Alder fission), in line with the fragmentation study of dihydroquercetin by Abad-Garcia et al. ${ }^{28}$ Detected peak with pseudomolecular ion $[\mathrm{M}-\mathrm{H}]^{-}$at $\mathrm{m} / z, 449$ and product ions at $\mathrm{m} / \mathrm{z} 303,285,151$ was tentatively identified as dihydroquercetin-rhamnoside (astilbin), in line with other reports. ${ }^{25,29}$ Dihydrokaempferol-hexoside was identified by its pseudomolecular ion $[\mathrm{M}-\mathrm{H}]^{-}$at $\mathrm{m} / \mathrm{z}, 449$ and product ions at $\mathrm{m} / \mathrm{z}, 287,269,151$ and dihydromyricetin-rhamnoside was identified by its pseudomolecular ion $[\mathrm{M}-\mathrm{H}]^{-}$at $\mathrm{m} / \mathrm{z} 465$ and product ions at $m / z 339,319,301,151$, as previously described.$^{30}$ The flavanonol profile of Nebbiolo veins was different comparing to the other studied varieties (Fig. 8C). Dihydroquercetin-hexoside (taxifolinhexoside) and dihydrokaempferol-hexoside were detected exclusively in Nebbiolo veins, where they comprised up to $51 \%$ of total flavanonols. Pinot noir, Cabernet Sauvignon and Barbera accumulated dihydromyricetin-rhamnoside and dihydroquercetin-rhamnoside whereas Shiraz and Grenache veins exclusively accumulated dihydroquercetin-rhamnoside. Dihydroquercetin-rhamnoside accumulated both in blades and veins and the highest concentration was found in Pinot noir veins where it ranged from 94.6 to $150.8 \mathrm{mg} \mathrm{kg}^{-1}$ (Fig. 8C, Supplementary Table 5).

\section{DISCUSSION}

\section{Genotypic and tissue-specific differences}

Among the analysed genotypes, Barbera showed some peculiar features: the lowest concentration of proanthocyanidins in blades was the prevalent trait. It is long-time known by viticulturists and it has recently been demonstrated that Barbera must is characterized by low proanthocyanidin amounts. ${ }^{31}$ Vice versa, Nebbiolo musts and wines owe their aging capability, among other factors, to the high proanthocyanidin content in berry skins. Apparently, this trait is evident also in leaves as Nebbiolo showed a higher capability of accumulating PA with respect to Barbera, both in blades and in veins early in the season, in line with what was previously reported by Margaria et al. ${ }^{18}$ comparing entire healthy leaves of the two varieties. At flowering the constitutive proanthocyanidin concentration of Barbera healthy leaves was half compared to that of Nebbiolo. When Merlot vines were 
treated with benzothiadiazole, a plant activator, to induce resistance against gray mold caused by Botrytis cinerea, the resistance was associated with an increase of total polyphenols in berry skins, in particular of the proanthocyanidin fraction that increased up to $36 \% .{ }^{32}$ All these information taken together allow speculating that constitutive higher amounts of polymeric proanthocyanidin could limit the diffusion of specific pathogens and contribute to explain the different levels of susceptibility of $V$. vinifera varieties to pathogens.

Veins were the exclusive leaf sector where anthocyanin accumulated as no anthocyanins accumulated in blades of healthy leaves (Fig. 9). The absence and/or traces of anthocyanins in healthy entire leaves were previously but rarely assessed in grapevine. ${ }^{19,20}$ Tri-hydroxylated anthocyanins and malvidin 3-O-glucoside were the prevalent anthocyanins in entire leaves of Cabernet Sauvignon and Sangiovese, with acyl-derivatives being around $61 \%$ of total concentrations. ${ }^{33}$ Although to our knowledge, no specific studies focused on leaf veins, previous work on petioles showed the sum of anthocyanin acyl-derivatives ranged from about 40 to $80 \%$ from end of July to leaf senescence in Barbera, ${ }^{34}$ in line with our data where they ranged from 50 to $90 \%$ (Fig. 2). Pinot noir represented the only exception as, similarly to berries, no acylated anthocyanins were found, underlying that in this cultivar acylation is inactive, regardless the organ. The complexity of the leaf anthocyanin profile was cultivar-related, Barbera being the genotype displaying the highest complexity, Pinot noir and Grenache, the lowest (Fig. 9).

Barbera and Grenache blades showed the highest flavonol concentration (as average values in the season), Nebbiolo the lowest. Flavonols identified in blades did not differ among genotypes with the exception of Nebbiolo and Grenache that accumulated a specific quercetin pentoside in veins. In vegetal tissues, flavonols play a role in thermal and excess energy dissipation and in photoprotection. Flavonols have been indicated as dampers of the abscisic acid dependent reactive oxygen species accumulation that drives stomatal closure and as molecules able to facilitate stomatal opening, modulating plant leaf gas exchange. ${ }^{35}$ This, together with the higher concentration of flavonols in specific genotypes could 
contribute to explain the cultivar-specific stomata opening mechanism. It is of particular interest in i) spreading further light on the possible relations between isohydric or anisohydric behaviour of grapevines and leaf flavonol accumulation and ii) studying the relation of grapevine varieties with fungus penetrating through stomata (such as Plasmopara viticola). Latouche and co-workers ${ }^{36}$ stated that constitutive higher amounts of flavonols (no information about specific molecules as they were estimated spectrophotometrically) slowed down the accumulation of stilbenoids in grapevine leaves, thus the phytoalexin-mediated response of leaves to Plasmopara attack was delayed. This opens the hypothesis that constitutive higher amounts of quercetin could at least limit the diffusion of specific pathogens.

Barbera leaves showed a peculiar trait as to hydroxycinnamic acids which concentration was much higher respect to the other examined biotypes, very clearly in blades (Fig. 9). Main leaf hydroxycinnamic acids did not differ among varieties and they were the same as in berries, ${ }^{9}$ with the only exception of Cabernet Sauvignon that accumulated one further type of hydroxycinnamic acid, tentatively identified as a caffeoyl hexoside, both in blades and in veins. Trans-caftaric acid was found to be the main non-flavonoid polyphenol in leaves and trans-form of HCA were always prevalent over cis-forms, as reported. ${ }^{2}$ Plant hydroxycinnamic acids are involved in defence mechanism and known to possess antimicrobial and antioxidative effects. ${ }^{37}$ In Arabidopsis it was shown that hydroxycinnamate accumulation increased following Botrytis cinerea infection ${ }^{38}$ and in Vitis vinifera cv Chardonnay a slight higher accumulation was detected after Oidium infection. ${ }^{39}$ Grapevine leaves of the present study were considered healthy (no signals of any kind of pathogens were found in collected leaves, total absence of eye-detectable spots, reddening in leaf blades and no trace of anthocyanins analytically detectable in blades). However, Barbera leaves displayed a much higher hydroxycinnamic acid concentration with respect to the other genotypes (Fig. 9) in line with what we previously and concomitantly found in other studies (data not shown). This suggests that there is a strong genotyperelated influence of hydroxycinnamic acid accumulation in leaves of Vitis vinifera varieties or that 
Barbera leaves of the present study were already reacting to a pathogen. In this second circumstance, further investigations would be necessary to understand if the accumulation of this class of non-flavonoid polyphenols could become an early indicator of grapevine sanitary status, well before the appearance of symptoms.

Little is known about flavan-3-ol profile variation in leaves of different Vitis vinifera varieties and accumulation during the vegetative season. The concentration of (+)-catechin and (-)-epicatechin was similar in leaf blades and veins, regardless of the variety. The concentration of epicatechin slightly increased in pear leaves after inoculation of Erwinia amylovora, ${ }^{40}$ a specific reaction to the disease implemented by the leaf tissue to limit its diffusion, exploiting the high activity of epicatechin as antioxidant. Moreover, epicatechin can also act as a modulator of cell-signalling, by inhibiting prooxidant enzymes, such as NADPH oxidases and lipoxygenases, by altering the phosphorylation state of was well represented in all the analysed biotypes, notably in veins. Nebbiolo, Pinot noir and Cabernet 
of epigallocatechin gallate, due to its high antioxidant capacity, are known (anti-carcinogenic, among others, through its capacity to limit cancer cell induction and proliferation, cardio- and neuroprotective, reviewed by Karas et al. $^{44}$ ). Constitutive high amounts of this monomeric proanthocyanidin could represent an important cultivar trait representing an element of protection against reactive oxygen species induced by stressors, including those of biotic origin.

To our knowledge, this is the first time that flavanonols are found in grapevine leaves, although astilbin was previously detected in Vitis vinifera stems. ${ }^{45,46}$ Astilbin was the exclusive flavanonol found in blades of all the examined varieties and in Shiraz and Grenache veins. The other studied genotypes also accumulated dihydromyricetin-rhamnoside and Nebbiolo was the cultivar that, besides displaying the highest flavanonol concentration, presented the widest profile differentiation, accumulating dihydroquercetin-hexoside (taxifolin-hexoside) and dihydrokaempferol-hexoside (Fig. 9), as well. These last two molecules are probably glucosides even though with our analytical tools we were not able to distinguish them from galactosides; however, we consider this unlikely, due to the wide presence of glucoside derivatives in Vitis vinifera, rather than galactosides. Flavanonols in plants have different ecological roles such as phytoalexins in $\operatorname{roots}^{47}$ or participants to plant anti-herbivore defence strategies. ${ }^{48}$ Astilbin, at relatively low concentration, was proved to be involved in the systemic induction response to fungal pathogens in Austrian pine. ${ }^{49}$ Moreover, dihydroquercetin (taxifolin) has promising therapeutic potential due to its effect on some anti-cancer mechanism, cholesterol biosynthesis and antiviral activity. ${ }^{50}$ Interestingly, flavanonol concentration was not negligible in the leaves of the six studied Vitis vinifera varieties and it was generally higher in veins respect to blades. Nebbiolo and to a lesser extent Pinot noir, displayed the highest flavanonol concentrations and, in the case of Nebbiolo also the widest profile complexity (Fig. 7 and Fig. 8). Nebbiolo, in particular, should be further investigated in the light of understanding its limited susceptibility to vein-located pathogens, such as Flavescence dorée ${ }^{18}$ and of studying grapevine interaction with herbivore insects as high concentration 
of flavanonols or of specific molecules among them, could be natural repellents for insects (including the vector of Flavescence dorée, Scaphoideus titanus).

Knowledge derived from the present work is a contribution to dissect leaf polyphenol potential as a part of grapevine defense mechanisms and of genotype-related susceptibility to pathogens. Moreover, current knowledge represents a starting point for future deepening about grapevine and vineyard by-products as source of bioactive phenolic compounds.

ACKNOWLEDGMENTS. Authors gratefully acknowledge Tiziano Strano, DISAFA, University of Turin, for managing the collection vineyard. Financial support from "Ricerca locale 2016 Caratterizzazione polifenolica di foglie di vite", University of Turin.

\section{Supporting Information.}

Supplement Table 1. The weather condition in the vineyard.

Supplement Table 2A. Average concentration of individual hydroxycinnamic acids in Vitis vinifera leaf blades.

Supplement Table 2B. Average concentration of individual hydroxycinnamic acids in Vitis vinifera leaf veins.

Supplement Table 3A. Average concentration of individual flavonols in Vitis vinifera blades.

Supplement Table 3B. Average concentration of individual flavonols in Vitis vinifera veins.

Supplement Table 4A. Average concentration of individual flavan-3-ols and flavanonols in Vitis vinifera leaf blades.

Supplement Table 4B. Average concentration of individual flavan-3-ols in Vitis vinifera veins.

Supplement Table 5. Average concentration of individual flavanonols in Vitis vinifera veins. 
Supplement Table 6. Average concentration of individual anthocyanins in Vitis vinifera veins.

488

489

490

491

492

493

494

495

496

497

498

499

500

501

502

503

504

505

506

507

508

509

510

511

Supplement Figure 1. HPLC-UV-ESI-MS/MS non-anthocyanin polyphenols of Nebbiolo leaf vein extract at $280 \mathrm{~nm}(\mathrm{~A}), 320 \mathrm{~nm}(\mathrm{~B})$ and $370 \mathrm{~nm}(\mathrm{C})$.

\section{REFERENCES}

(1) Lacombe, T.; Boursiquot, J. M.; Laucou, V.; Di Vecchi-Staraz, M.; Péros, J. P.; This, P. Largescale parentage analysis in an extended set of grapevine cultivars (Vitis vinifera L.). Theor. Appl. Genet. 2013, 126 (2), 401-414.

(2) Fernandes, F.; Ramalhosa, E.; Pires, P.; Verdial, J.; Valentão, P.; Andrade, P.; Bento, A.; Pereira, J. A. Vitis vinifera leaves towards bioactivity. Ind. Crops Prod. 2013, 43 (1), 434-440.

(3) Püssa, T.; Floren, J.; Kuldkepp, P.; Raal, A. Survey of grapevine Vitis vinifera stem polyphenols by liquid chromatography-diode array detection-tandem mass spectrometry. J. Agric. Food Chem. 2006, 54 (20), 7488-7494.

(4) Georgiev, V.; Ananga, A.; Tsolova, V. Recent advances and uses of grape flavonoids as nutraceuticals. Nutrients 2014, 6 (1), 391-415.

(5) Lima, A.; Bento, A.; Baraldi, I.; Malheiro, R. Selection of grapevine leaf varieties for culinary process based on phytochemical composition and antioxidant properties. Food Chem. 2016, 212, 291-295.

(6) Dixon, R. A.; Lamb, C. J. Molecular communication in interactions between plants and microbial pathogens. Annu. Rev. Plant Physiol. Plant Mol. Biol. 1990, 41, 339-367.

(7) Mattivi, F.; Guzzon, R.; Vrhovsek, U.; Stefanini, M.; Velasco, R. Metabolite profiling of grapes: flavonols and anthocyanins. J. Agric. Food Chem. 2006, 54, 7692-7702.

(8) Ferrandino, A.; Guidoni, S. Anthocyanins, flavonols and hydroxycinnamates: An attempt to use them to discriminate Vitis vinifera L. cv "Barbera" clones. Eur. Food Res. Technol. 2010, 230 (3), 417-427.

(9) Ferrandino, A.; Carra, A.; Rolle, L.; Schneider, A.; Schubert, A. Profiling of hydroxycinnamoyl 
tartrates and acylated anthocyanins in the skin of 34 Vitis vinifera genotypes. J. Agric. Food Chem. 2012, 60 (19), 4931-4945.

514

515

(10) Figueiredo, A.; Fortes, A. M.; Ferreira, S.; Sebastiana, M.; Choi, Y. H.; Sousa, L.; Acioli-Santos, B.; Pessoa, F.; Verpoorte, R.; Pais, M. S. Transcriptional and metabolic profiling of grape (Vitis vinifera L.) leaves unravel possible innate resistance against pathogenic fungi. J. Exp. Bot. 2008, 59 (12), 3371-3381.

(11) Catoni, M.; Falsone, G.; Bonifacio, E. Assessing the origin of carbonates in a complex soil with a suite of analytical methods. Geoderma 2012, 176, 47-57.

(12) Abascal, K.; Ganora, L.; Yarnell, E. The effect of freeze-drying and its implications for botanical medicine: a review. Phyther. Res. 2005, 19 (8), 655-660.

(13) Harbertson, J. F.; Mireles, M.; Yu, Y. Improvement of BSA tannin precipitation assay by reformulation of resuspension buffer. Am. J. Enol. Vitic. 2015, 66 (1), 95-99.

(14) Di Stefano, R.; Cravero, M. C. The separation of hydroxycinnamates in wine. Sci. des Aliment. 1992, No. 12, 139-144.

(15) Maier, T.; Schieber, A.; Kammerer, D. R.; Carle, R. Residues of grape (Vitis vinifera L.) seed oil production as a valuable source of phenolic antioxidants. Food Chem. 2009, 112 (3), 551-559.

(16) Rezaei, S.; Rezaei, K.; Haghighi, M.; Labbafi, M. Solvent and solvent to sample ratio as main parameters in the microwave-assisted extraction of polyphenolic compounds from apple pomace. Food Sci. Biotechnol. 2013, 22 (5), 1-6.

(17) Rusjan, D.; Halbwirth, H.; Stich, K.; Mikulič-Petkovšek, M.; Veberič, R. Biochemical response of grapevine variety "Chardonnay" (Vitis vinifera L.) to infection with grapevine yellows (Bois noir). Eur. J. Plant Pathol. 2012, 134 (2), 231-237.

(18) Margaria, P.; Ferrandino, A.; Caciagli, P.; Kedrina, O.; Schubert, A.; Palmano, S. Metabolic and transcript analysis of the flavonoid pathway in diseased and recovered Nebbiolo and Barbera grapevines (Vitis vinifera L.) following infection by Flavescence dorée phytoplasma. Plant, Cell 
Environ. 2014, 37 (9), 2183-2200.

(19) Gutha, L. R.; Casassa, L. F.; Harbertson, J. F.; Naidu, R. A. Modulation of flavonoid biosynthetic pathway genes and anthocyanins due to virus infection in grapevine (Vitis vinifera L.) leaves. BMC Plant Biol. 2010, 10, 187.

(20) Guidoni, S.; Mannini, F.; Ferrandino, A.; Argamante, N.; Di Stefano, R. The effect of grapevine leafroll and rugose wood sanitation on agronomic performance and berry and leaf phenolic content of a Nebbiolo clone (Vitis vinifera L.). Am. J. Enol. Vitic. 1997, 48 (4), 438-442.

(21) Chen, H. J.; Inbaraj, B. S.; Chen, B. H. Determination of phenolic acids and flavonoids in Taraxacum formosanum kitam by liquid chromatography-tandem mass spectrometry coupled with a post-column derivatization technique. Int. J. Mol. Sci. 2012, 13 (1), 260-285.

(22) Perestrelo, R.; Lu, Y.; Santos, S. A. O.; Silvestre, A. J. D.; Neto, C. P.; Câmara, J. S.; Rocha, S. M. Phenolic profile of Sercial and Tinta Negra Vitis vinifera L. grape skins by HPLC-DAD-ESIMSn: Novel phenolic compounds in Vitis vinifera L. grape. Food Chem. 2012, 135 (1), 94-104.

(23) Topalovic, A.; Mikulic-Petkovsek, M.; Perovic, N.; Trifunovic, S.; Knezevic, M. Phenolic composition of the leaf of grapevine cv. "Cardinal.” Agric. For. 2012, 52 (6), 5-15.

(24) Peng, Q. Z.; Zhu, Y.; Liu, Z.; Du, C.; Li, K. G.; Xie, D. Y. An integrated approach to demonstrating the ANR pathway of proanthocyanidin biosynthesis in plants. Planta 2012, 236 (3), 901-918.

(25) Flamini, R. Recent applications of mass spectrometry in the study of grape and wine polyphenols. ISRN Spectrosc. 2013, 2013, 45.

(26) Alonso, R.; Berli, F. J.; Fontana, A.; Piccoli, P.; Bottini, R. Malbec grape (Vitis vinifera L.) responses to the environment: Berry phenolics as influenced by solar UV-B, water deficit and sprayed abscisic acid. Plant Physiol. Biochem. 2016, 109, 84-90.

(27) Landrault, N.; Larronde, F.; Delaunay, J. C.; Castagnino, C.; Vercauteren, J.; Merillon, J. M.; Gasc, F.; Cros, G.; Teissedre, P. L. Levels of stilbene oligomers and astilbin in French varietal 
wines and in grapes during noble rot development. J. Agric. Food Chem. 2002, 50 (7), 2046-

563

564

565

566

567

568

569

570

571

572

573

574

575

576

577

578

579

580

581

582

583

584

585

586 2052.

(28) Abad-Garcia, B.; Garmon-Lobato, S.; Berrueta, L. A.; Gallo, B.; Vicente, F. A fragmentation study of dihydroquercetin using triple quadrupole mass spectrometry and its application for identification of dihydroflavonols in Citrus juices. Rapid Commun. Mass Spectrom. 2009, 24 (24), 2785-2792.

(29) Thuan, N. H.; Malla, S.; Trung, N. T.; Dhakal, D.; Pokhrel, A. R.; Chu, L. L.; Sohng, J. K. Microbial production of astilbin, a bioactive rhamnosylated flavanonol, from taxifolin. World J. Microbiol. Biotechnol. 2017, 33 (2), 1-10.

(30) Ivanova, V.; Dörnyei, Á.; Márk, L.; Vojnoski, B.; Stafilov, T.; Stefova, M.; Kilár, F. Polyphenolic content of Vranec wines produced by different vinification conditions. Food Chem. 2011, 124 (1), 316-325.

(31) Asproudi, A.; Piano, F.; Anselmi, G.; Di Stefano, R.; Bertolone, E.; Borsa, D. Proanthocyanidin composition and evolution during grape ripening as affected by variety: Nebbiolo and Barbera cv. J. Int. des Sci. la Vigne du Vin 2015, 49 (1), 59-69.

(32) Iriti, M.; Rossoni, M.; Borgo, M.; Faoro, F. Benzothiadiazole enhances resveratrol and anthocyanin biosynthesis in grapevine, meanwhile improving resistance to Botrytis cinerea. $J$. Agric. Food Chem. 2004, 52 (14), 4406-4413.

(33) Caramanico, L.; Rustioni, L.; De Lorenzis, G. Iron deficiency stimulates anthocyanin accumulation in grapevine apical leaves. Plant Physiol. Biochem. 2017, 119, 286-293.

(34) Di Stefano, R.; Maggiorotto, G. Anthocyanins, hydroxycinnamic acids and flavonols in berries, leaves, stems and shoots of vine. Riv. di Vitic. e di Enol. 1995, No. 2, 51-65.

(35) Watkins, J.; Chapman, J. M.; Muday, G. K. Abscisic acid-induced reactive oxygen species are modulated by flavonols to control stomata aperture. Plant Physiol. 2017, 175 (4), 1807-1825.

(36) Latouche, G.; Bellow, S.; Poutaraud, A.; Meyer, S.; Cerovic, Z. G. Influence of constitutive 
phenolic compounds on the response of grapevine (Vitis vinifera L.) leaves to infection by Plasmopara viticola. Planta 2013, 237 (1), 351-361.

(37) El-Seedi, H. R.; El-Said, A. M. A.; Khalifa, S. A. M.; Göransson, U.; Bohlin, L.; Borg-Karlson, A. K.; Verpoorte, R. Biosynthesis, natural sources, dietary intake, pharmacokinetic properties, and biological activities of hydroxycinnamic acids. J. Agric. Food Chem. 2012, 60 (44), 1087710895.

(38) Lloyd, A. J.; William Allwood, J.; Winder, C. L.; Dunn, W. B.; Heald, J. K.; Cristescu, S. M.; Sivakumaran, A.; Harren, F. J. M.; Mulema, J.; Denby, K.; et al. Metabolomic approaches reveal that cell wall modifications play a major role in ethylene-mediated resistance against Botrytis cinerea. Plant J. 2011, 67 (5), 852-868.

(39) Stummer, B. E.; Francis, I. L.; Zanker, T.; Lattey, K. A.; Scott, E. S. Effects of powdery mildew on the sensory properties and composition of Chardonnay juice and wine when grape sugar ripeness is standardised. Aust. J. Grape Wine Res. 2005, 11 (1), 66-76.

(40) Vrancken, K.; Holtappels, M.; Schoofs, H.; Deckers, T.; Treutter, D.; Valcke, R. Erwinia amylovora affects the phenylpropanoid-flavonoid pathway in mature leaves of Pyrus communis cv. Conférence. Plant Physiol. Biochem. 2013, 72, 134-144.

(41) Treutter, D. Significance of flavonoids in plant resistance and enhancement of their biosynthesis. Plant Biol. 2005, 7 (6), 581-591.

(42) Golba, B.; Treutter, D.; Kollar, A. Effects of apple (Malus $\times$ domestica Borkh.) phenolic compounds on proteins and cell wall-degrading enzymes of Venturia inaequalis. Trees - Struct. Funct. 2012, 26 (1), 131-139.

(43) Rashed, A.; Daugherty, M. P.; Almeida, R. P. P. Grapevine genotype susceptibility to Xylella fastidiosa does not predict vector transmission success. Environ. Entomol. 2011, 40 (5), 11921199.

(44) Karas, D.; Ulrichov, J. Galloylation of polyphenols alters their biological activity. Food Chem. 
Toxicol. 2017, 105, 223-240.

(45) Souquet, J.; Labarbe, B.; Le Guernevé, C.; Cheynier, V.; Moutounet, M. Phenolic composition of grape stems. J. Agric. Food Chem. 2000, 48, 1076-1080.

(46) Makris, D. P.; Boskou, G.; Andrikopoulos, N. K.; Kefalas, P. Characterisation of certain major polyphenolic antioxidants in grape (Vitis vinifera $\mathrm{cv}$. Roditis) stems by liquid chromatographymass spectrometry. Eur. Food Res. Technol. 2008, 226 (5), 1075-1079.

(47) Harborne, J. B. The comparative biochemistry of phytoalexins induction in plants. Biochem Syst Ecol 1999, 27, 335-367.

(48) Kidd, N. A. C. Resource deprival as an anti-herbivore strategy in plants, with particular reference to aphids. Eur. J. Entomol. 1994, 91, 53-56.

(49) Sherwood, P.; Bonello, P. Austrian pine phenolics are likely contributors to systemic induced resistance against diplodia pinea. Tree Physiol. 2013, 33 (8), 845-854.

(50) Weidmann, A. E. Dihydroquercetin: More than just an impurity? Eur. J. Pharmacol. 2012, 684 (1-3), 19-26. 
630 Figure 1. Changes in the total polyphenol (TP) and total proanthocyanidin (PA) concentration in Vitis vinifera leaves during the season. $\mathrm{A}$ and $\mathrm{C}=$ blades; $\mathrm{B}$ and $\mathrm{D}=$ veins. Means \pm standard errors $(\mathrm{n}=3)$.

Figure 2. Accumulation of anthocyanins in Vitis vinifera leaf veins during the season. A = evolution of total anthocyanins (TA); results (means \pm standard errors, $n=3$ ) are expressed as $\mathrm{mg}$ of malvidin 3-Oglucoside equivalent per $\mathrm{kg}$ of leaf vein fresh weight $(\mathrm{FW}) . \mathrm{B}=$ anthocyanin profile of leaf veins during the vegetative season. $\mathrm{NE}=$ Nebbiolo; $\mathrm{BR}=$ Barbera; $\mathrm{PN}=$ Pinot noir; $\mathrm{CS}=$ Cabernet Sauvignon; GR $=$ Grenache; $S R=$ Shiraz. Numbers after the variety acronyms refer to: $1=$ DOY $142\left(22^{\text {nd }}\right.$ of May); 2 $=$ DOY 183 ( $2^{\text {nd }}$ of July); $3=$ DOY 197 (16 ${ }^{\text {th }}$ of July); $4=$ DOY $210\left(29^{\text {th }}\right.$ of July) and $5=$ DOY 238 ( $26^{\text {th }}$ of August).

Figure 3. HPLC-UV-MS/MS chromatogram of Barbera leaf vein anthocyanins; sampling date at DOY 142 ( $22^{\text {nd }}$ of May). See Table 3 for peak identification.

Figure 4. Accumulation of flavonols in Vitis vinifera leaves during the season. Evolution of total flavonols in blades (A) and in veins (B); means of the sum of detected flavonols \pm standard errors $(n=3)$. Flavonol profile of leaf blades (C) and veins (D) during the season; Q - quercetin, K - kaempferol, Myr - myricetin, Gluc - glucuronide, Glc - glucoside; see Fig. 2 for variety acronym identification.

Figure 5. Accumulation of hydroxycinnamic acids (HCA) in Vitis vinifera leaves during the season. Evolution of total HCA in blades (A) and veins (B); means of the sum of all detected HCA \pm standard errors $(n=3)$. Profile of HCA of leaf blades (C) and veins (D) during the season; see Fig. 2 for variety acronym identification.

Figure 6. Accumulation of flavan-3-ols in Vitis vinifera leaves during the season. Evolution of total flavan-3-ols in blades (A) and veins (B); means of the sum of all detected flavan-3-ols \pm standard errors $(n=3)$. Flavan-3-ol profile of leaf blades (C) and veins (D) during the season; see Fig. 2 for variety acronym identification.

Figure 7. The extracted ion chromatogram (EIC) at m/z 465 (A) and m/z 449 (B) in negative mode; UV maximum and product ion spectra at negative mode of dihydroquercetin-hexoside (1); dihydromyricetinrhamnoside (2); dihydrokaempferol-hexoside (3) and dihydroquercetin-rhamnoside (4, astilbin) detected in Nebbiolo leaf vein extracts.

Figure 8. Accumulation of flavanonols in Vitis vinifera leaves during the season. Evolution of total flavanonols in blades (A; exclusively dihydroquercetin-rhamnoside, astilbin) and veins (B); means of the sum of all detected flavanonols \pm standard errors $(n=3)$. Flavanonol profile of leaf veins $(C)$ during the season; see Fig. 2 for variety acronym identification.

Figure 9. Evolution of polyphenol concentration in the leaves of six Vitis vinifera varieties. Heatmap of blades and veins represent Z-scores of each compound calculated by subtracting to each average value (variety and date) the general average of the entire population divided by the standard deviation. See Fig. 2 for variety acronym identification. 
Table 1. Dry matter $(\%)$ in Vitis vinifera leaves during the vegetative season ${ }^{a}$.

\begin{tabular}{|c|c|c|c|c|c|}
\hline & & DOY 186 & DOY 200 & $D O Y 241$ & date \\
\hline \multirow[t]{8}{*}{ blades } & $\mathrm{NE}$ & $30.87 \pm 0.16$ & $33.61 \pm 0.04$ & $35.90 \pm 0.26$ & $* *$ \\
\hline & $\mathrm{CS}$ & $30.77 \pm 0.18$ & $30.92 \pm 0.39$ & $34.11 \pm 0.57$ & $* *$ \\
\hline & $\mathrm{BR}$ & $31.60 \pm 0.35$ & $33.42 \pm 0.83$ & $35.28 \pm 0.92$ & * \\
\hline & GR & $28.66 \pm 0.62$ & $27.58 \pm 0.82$ & $30.76 \pm 1.23$ & ns \\
\hline & $\mathrm{PN}$ & $30.44 \pm 0.80$ & $32.69 \pm 1.10$ & $31.19 \pm 4.37$ & ns \\
\hline & $\mathrm{SH}$ & $31.30 \pm 1.97$ & $32.29 \pm 1.37$ & $36.59 \pm 1.68$ & ns \\
\hline & average & $30.61 \pm 0.39$ & $31.75 \pm 0.58$ & $33.97 \pm 0.88$ & \\
\hline & variety & ns & $* *$ & $\mathrm{~ns}$ & \\
\hline \multirow[t]{8}{*}{ veins } & $\mathrm{NE}$ & $22.09 \pm 1.13$ & $24.12 \pm 0.36$ & $26.10 \pm 0.63$ & * \\
\hline & CS & $18.92 \pm 0.32$ & $21.57 \pm 0.47$ & $23.28 \pm 0.80$ & $* *$ \\
\hline & $\mathrm{BR}$ & $20.92 \pm 1.35$ & $23.76 \pm 0.79$ & $25.67 \pm 1.33$ & ns \\
\hline & GR & $19.39 \pm 0.61$ & $20.39 \pm 0.37$ & $23.42 \pm 0.77$ & $* *$ \\
\hline & $\mathrm{PN}$ & $20.72 \pm 0.97$ & $21.26 \pm 0.90$ & $27.57 \pm 1.81$ & * \\
\hline & $\mathrm{SH}$ & $21.67 \pm 1.25$ & $22.19 \pm 0.74$ & $25.39 \pm 0.94$ & ns \\
\hline & average & $20.62 \pm 0.44$ & $22.22 \pm 0.39$ & $25.24 \pm 0.53$ & \\
\hline & variety & $\mathrm{ns}$ & $* *$ & $\mathrm{~ns}$ & \\
\hline
\end{tabular}

${ }^{a}$ Means \pm standard errors $(\mathrm{n}=3)$. Means were separated by ANOVA and significant differences among dates (rows) or varieties (columns) were evaluated by the Tukey-b test, $\mathrm{p} \leq 0.05\left(^{*}\right), \mathrm{p} \leq 0.01(* *)$; ns - not significant. Day of year (DOY) refers to $186-5^{\text {th }}$ of July, $200-19^{\text {th }}$ of July and $241-29^{\text {th }}$ of July. 
Table 2. Solvent and sample/volume ratio influence on Vitis vinifera leaf total polyphenols and total flavonoids.

\begin{tabular}{|c|c|c|c|c|c|c|c|}
\hline & & \multicolumn{3}{|c|}{ blades } & \multicolumn{3}{|c|}{ veins } \\
\hline solvent & $\mathrm{pH}$ & SSR & $\begin{array}{c}\text { total } \\
\text { polyphenols }\end{array}$ & $\begin{array}{c}\text { total } \\
\text { flavonoids }^{b}\end{array}$ & SSR & $\begin{array}{c}\text { total } \\
\text { polyphenols }\end{array}$ & $\begin{array}{c}\text { total } \\
\text { flavonoids }^{b}\end{array}$ \\
\hline $\begin{array}{c}\text { hydroalcoholic buffer } \\
\text { ethanol } 12 \%\end{array}$ & 3.2 & $10: 1$ & $28.60 \pm 3.41 b$ & $39.14 \pm 4.42 \mathrm{ab}$ & $20: 1$ & $16.98 \pm 2.27 \mathrm{~b}$ & $27.13 \pm 3.30 \mathrm{ab}$ \\
\hline methanol-water (80/20) & 4.6 & $10: 1$ & $17.05 \pm 1.13 \mathrm{a}$ & $31.79 \pm 2.07 \mathrm{a}$ & $20: 1$ & $8.50 \pm 1.25 \mathrm{a}$ & $18.39 \pm 1.93 \mathrm{a}$ \\
\hline $\begin{array}{c}\text { methanol-water }(80 / 20) \\
\text { with } \mathrm{HCl} 0.1 \%\end{array}$ & 3.5 & $10: 1$ & $16.97 \pm 1.74 \mathrm{a}$ & $29.54 \pm 1.85 \mathrm{a}$ & $20: 1$ & $9.06 \pm 1.62 \mathrm{a}$ & nd \\
\hline acetone-water (50/50) & 5.6 & $10: 1$ & $21.99 \pm 0.43 \mathrm{ab}$ & $26.06 \pm 2.57 \mathrm{a}$ & $20: 1$ & $10.98 \pm 0.92 \mathrm{a}$ & $17.54 \pm 1.41 \mathrm{a}$ \\
\hline $\begin{array}{c}\text { acetone-water (50/50) } \\
\text { with } \mathrm{HCl} 0.1 \%\end{array}$ & 3.3 & $10: 1$ & $21.65 \pm 1.03 \mathrm{ab}$ & $26.11 \pm 2.70 \mathrm{a}$ & $20: 1$ & $11.57 \pm 0.71 \mathrm{a}$ & $19.90 \pm 2.01 \mathrm{a}$ \\
\hline $\begin{array}{c}\text { phosphate-citrate } \\
\text { buffer }\end{array}$ & 3.6 & $10: 1$ & $13.72 \pm 2.37 \mathrm{a}$ & $30.45 \pm 1.90 \mathrm{a}$ & $20: 1$ & $5.42 \pm 0.77 \mathrm{a}$ & nd \\
\hline $\begin{array}{c}\text { hydroalcoholic buffer } \\
\text { ethanol } 40 \%\end{array}$ & 3.9 & $10: 1$ & $27.90 \pm 1.17 \mathrm{~b}$ & $48.17 \pm 3.32 \mathrm{ab}$ & $20: 1$ & $18.03 \pm 1.05 b$ & $33.64 \pm 0.96 b$ \\
\hline $\begin{array}{c}\text { hydroalcoholic buffer } \\
\text { ethanol } 40 \%\end{array}$ & 3.9 & $25: 1$ & $46.11 \pm 2.07$ & $59.17 \pm 2.87$ & $25: 1$ & $25.08 \pm 2.76$ & $24.18 \pm 2.44$ \\
\hline
\end{tabular}

$\overline{a, b}$ Means \pm standard errors ( $\mathrm{n}=3$ ) as grams of catechin (CE)/kg of Nebbiolo leaf fresh weight. Means were separated by ANOVA and significant differences among solvents were evaluated by Tukey-b test, $\mathrm{p} \leq 0.05$; nd - not detected; SSR sample volume ratio. 
Table 3. Identified anthocyanins in Vitis vinifera leaf veins by HPLC-ESI-MS/MS

\begin{tabular}{ccccc}
$\mathbf{I D}^{\boldsymbol{a}}$ & $\begin{array}{c}\mathbf{R t} \\
(\mathbf{0} \mathbf{2} \mathbf{~} \mathbf{~ m i n})\end{array}$ & $\begin{array}{c}{[\mathbf{M}]^{+}} \\
(\mathbf{m} / \mathbf{z})\end{array}$ & $\begin{array}{c}{\left[\mathbf{M S}^{2}\right]^{+}} \\
(\mathbf{m} / \mathbf{z})\end{array}$ & identification $^{b}$ \\
\hline $\mathbf{1}$ & 21.9 & 463 & 301 & peonidin 3- $O$-glucoside \\
$\mathbf{2}$ & 23.1 & 493 & 331 & malvidin 3-O-glucoside \\
$\mathbf{3}$ & 35.2 & 657 & 303 & unknown \\
$\mathbf{4}$ & 37.0 & 611 & 303 & delphinidin 3- $O$-(p-coum) \\
$\mathbf{5}$ & 39.2 & 655 & 331 & malvidin 3- $O$-(caff) \\
$\mathbf{6}$ & 40.5 & 595 & 287 & cyanidin 3- $O$-(p-coum) \\
$\mathbf{7}$ & 42.0 & 625 & 317 & petunidin 3- $O$-(p-coum) \\
$\mathbf{8}$ & 45.1 & 609 & 301 & peonidin 3- $O$-(p-coum) \\
$\mathbf{9}$ & 45.8 & 639 & 331 & malvidin 3- $O$-(p-coum) \\
\hline
\end{tabular}

${ }^{a}$ ID identification numbers corresponding to peaks reported in Figure 3 . ${ }^{b}$ p-coum - p-coumaroyl derivatives; caff - caffeoyl derivatives. 
Table 4. Identified non-anthocyanin phenolic compounds in Vitis vinifera leaf blades and veins by HPLC-ESI-MS/MS

\begin{tabular}{|c|c|c|c|c|c|c|}
\hline $\mathrm{ID}^{a}$ & $\begin{array}{c}\mathrm{Rt} \\
( \pm 0.2 \mathrm{~min})\end{array}$ & $\begin{array}{l}{[\mathrm{M}]^{-}} \\
(\mathbf{m} / \mathbf{z})\end{array}$ & $\begin{array}{r}{\left[\mathbf{M S}^{2}\right]^{-}} \\
(\mathbf{m} / \mathbf{z})\end{array}$ & $\begin{array}{l}{[\mathbf{M}]^{+}} \\
(\mathbf{m} / \mathbf{z})\end{array}$ & $\underset{(\mathbf{m} / \mathbf{z})}{\left[\mathbf{M S}^{2}\right]^{+}}$ & compound identification \\
\hline 1 & 16.9 & 593 & $425,407,289$ & 595 & 291 & $\begin{array}{l}\text { (epi)gallocatechin- (epi)catechin } \\
\text { (isomer I) }\end{array}$ \\
\hline 2 & 18.0 & 593 & $425,407,289$ & & & $\begin{array}{l}\text { (epi)gallocatechin- (epi)catechin } \\
\text { (isomer II) }\end{array}$ \\
\hline 3 & 18.7 & 315 & 153 & & & protocatechuic acid-glucoside \\
\hline 4 & 19.9 & 593 & $425,407,289$ & 595 & 291 & $\begin{array}{l}\text { (epi)gallocatechin- (epi)catechin } \\
\text { (isomer III) }\end{array}$ \\
\hline 5 & 20.7 & 311 & 179 & & & cis-caftaric acid \\
\hline 6 & 21.2 & 577 & $451,425,289$ & & & procyanidin $\mathrm{B}_{3}$ \\
\hline 7 & 22.0 & 311 & 179 & & & trans-caftaric acid \\
\hline 8 & 23.3 & 289 & $245,205,179$ & 291 & $273,165,123$ & $(+)$-catechin \\
\hline 9 & 24.0 & 577 & $451,425,289$ & 579 & 561,427 & procyanidin $\mathrm{B}_{1}$ \\
\hline 10 & 24.7 & 295 & 163 & & & cis-coutaric acid \\
\hline 11 & 25.0 & 341 & 179 & & & caffeoyl-hexoside \\
\hline 12 & 25.7 & 295 & 163 & & & trans-coutaric acid \\
\hline 13 & 26.4 & 325 & 193 & & & fertaric acid \\
\hline 14 & 27.6 & 289 & $245,205,177$ & 291 & $273,165,139$ & (-)-epicatechin \\
\hline 15 & 29.6 & 465 & $303,285,151$ & & & $\begin{array}{l}\text { dihydroquercetin-hexoside } \\
\text { (taxifolin-hexoside) }\end{array}$ \\
\hline 16 & 31.2 & 465 & $339,319,151$ & & & $\begin{array}{l}\text { dihydromyricetin-rhamnoside } \\
\text { (ampelopsin-rhamnoside) }\end{array}$ \\
\hline 17 & 32.9 & 449 & $287,269,151$ & & & $\begin{array}{l}\text { dihydrokaempferol-hexoside } \\
\text { (aromadendrin-hexoside) }\end{array}$ \\
\hline 18 & 33.8 & 479 & 317 & 481 & 319 & myricetin 3-O-glucoside \\
\hline 19 & 34.6 & 493 & 317 & 495 & 319 & myricetin 3-O-glucuronide \\
\hline 20 & 35.5 & 449 & $303,285,151$ & & & $\begin{array}{l}\text { dihydroquercetin-rhamnoside } \\
\text { (astilbin) }\end{array}$ \\
\hline 21 & 36.3 & 433 & 301 & 435 & 303 & quercetin-pentoside \\
\hline 22 & 36.7 & 463 & 301 & 465 & 303 & quercetin 3-O-glucoside \\
\hline 23 & 37.5 & 477 & 301 & 479 & 303 & quercetin 3-glucuronide \\
\hline 24 & 38.8 & 447 & 285 & 449 & 287 & kaempferol 3-O-glucoside \\
\hline 25 & 39.2 & 461 & 285 & 463 & 287 & kaempferol 3-O-glucuronide \\
\hline
\end{tabular}

${ }^{a} \mathrm{ID}$ numbers correpsond to peaks reported in Supplement Figure 1. 

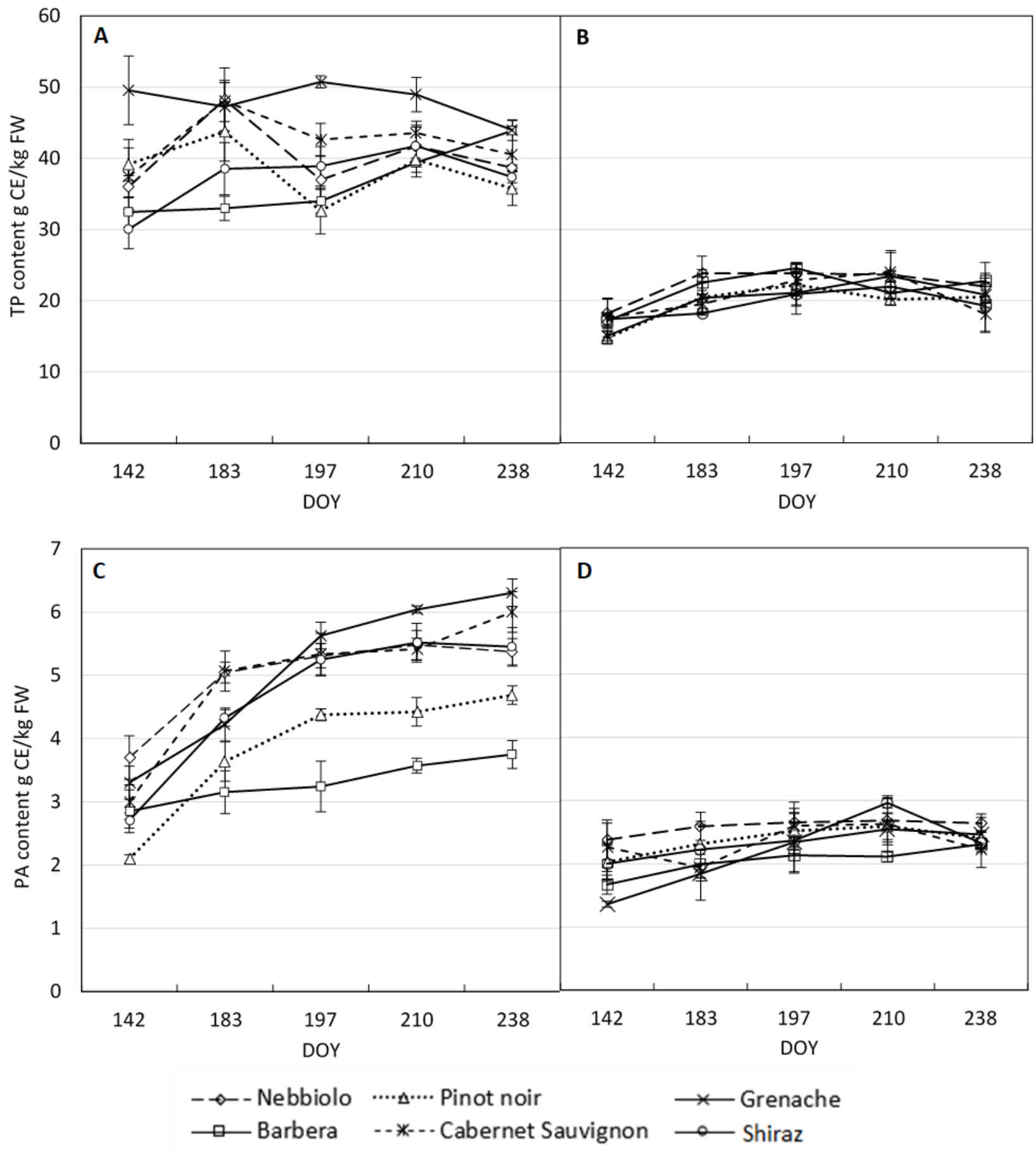

Figure 1 

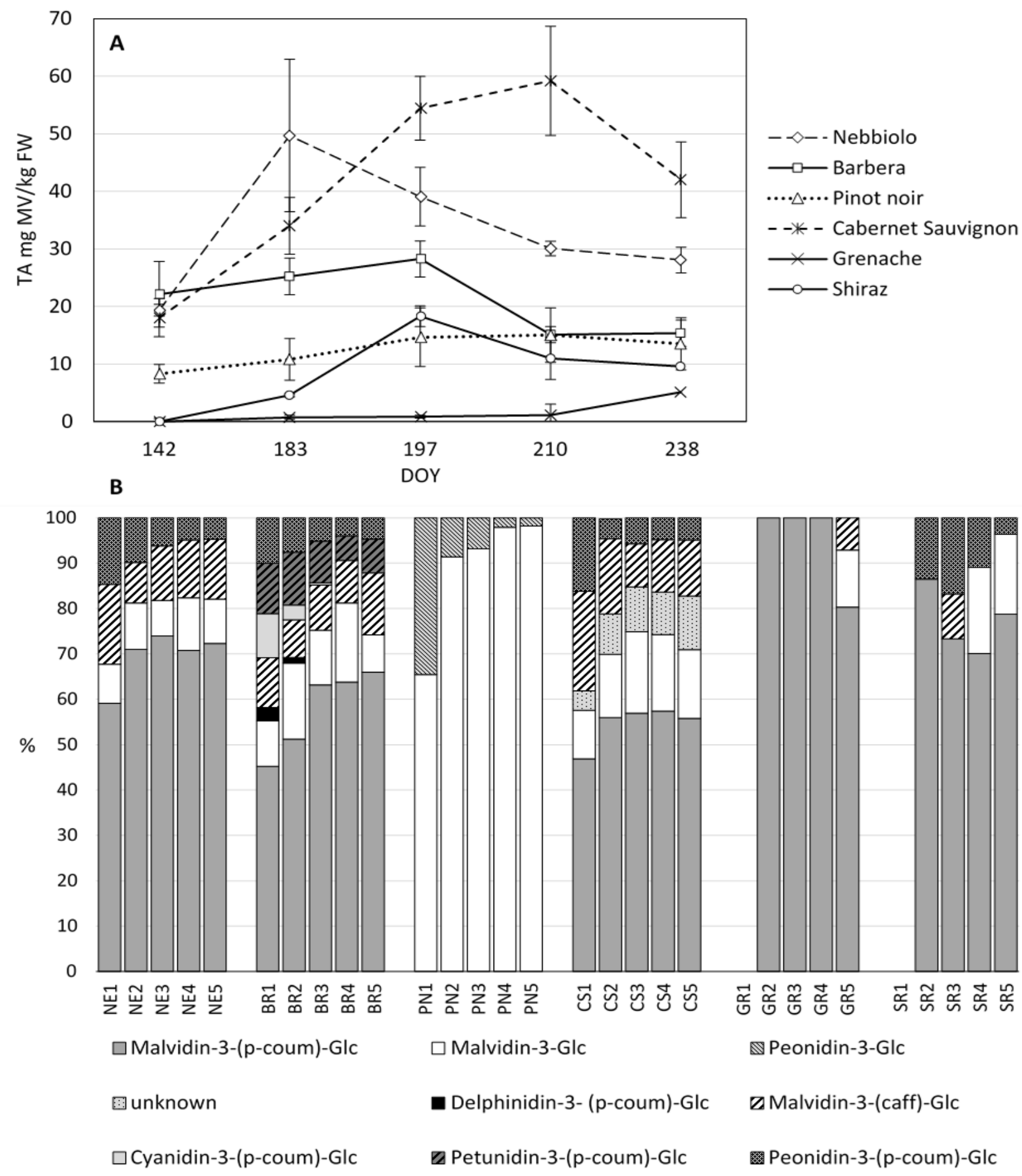

Figure 2 


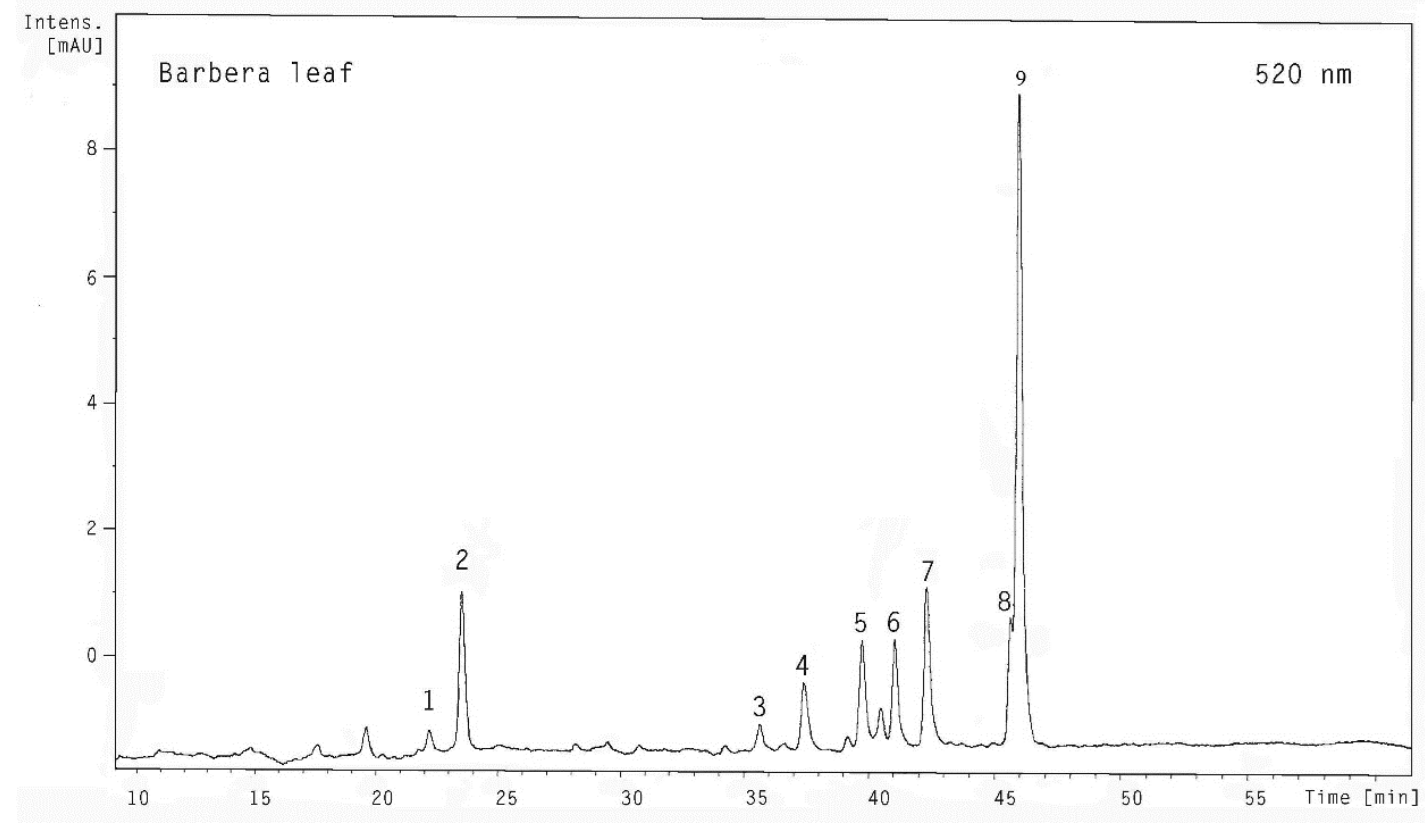

Figure 3 

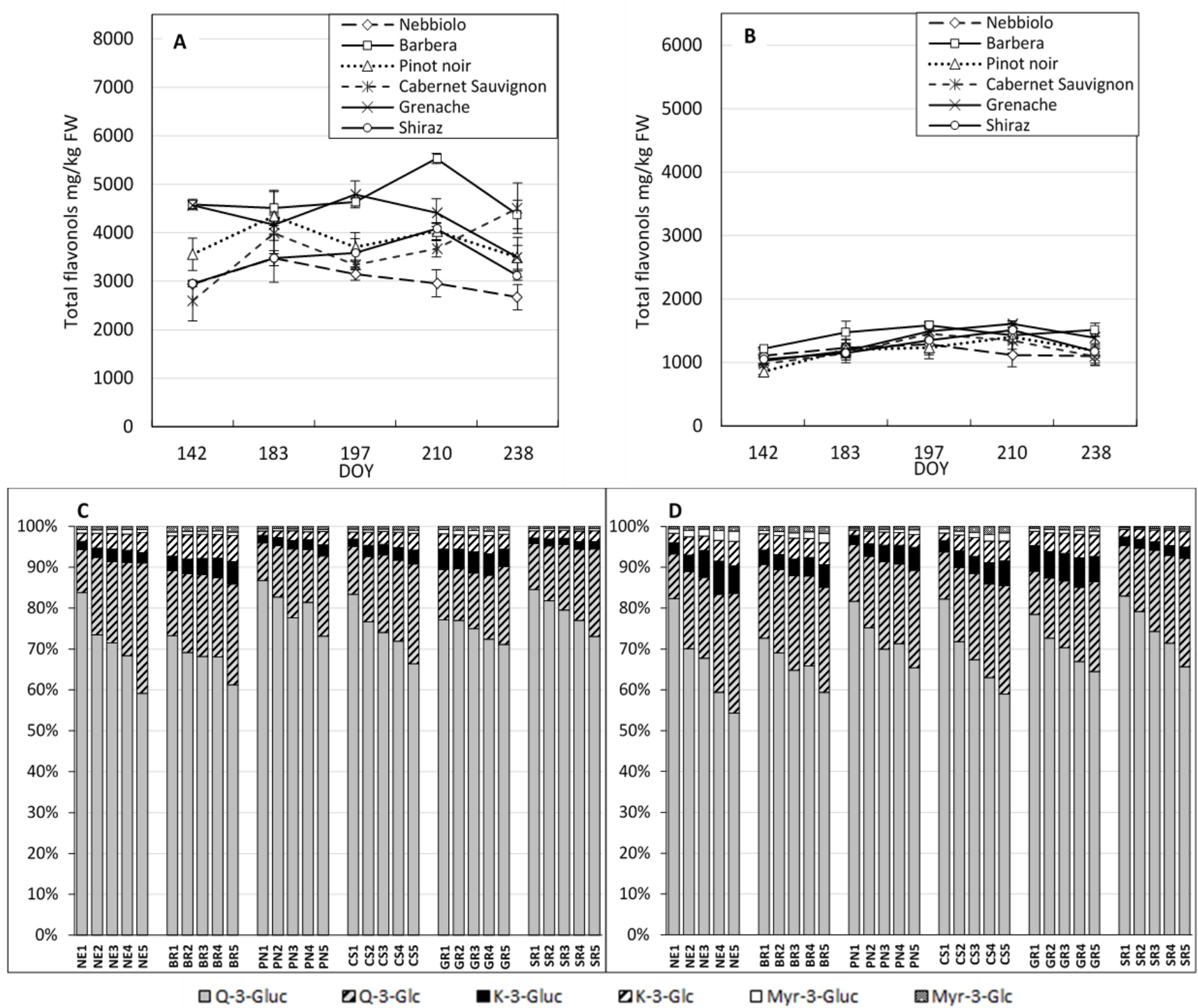

Figure 4 

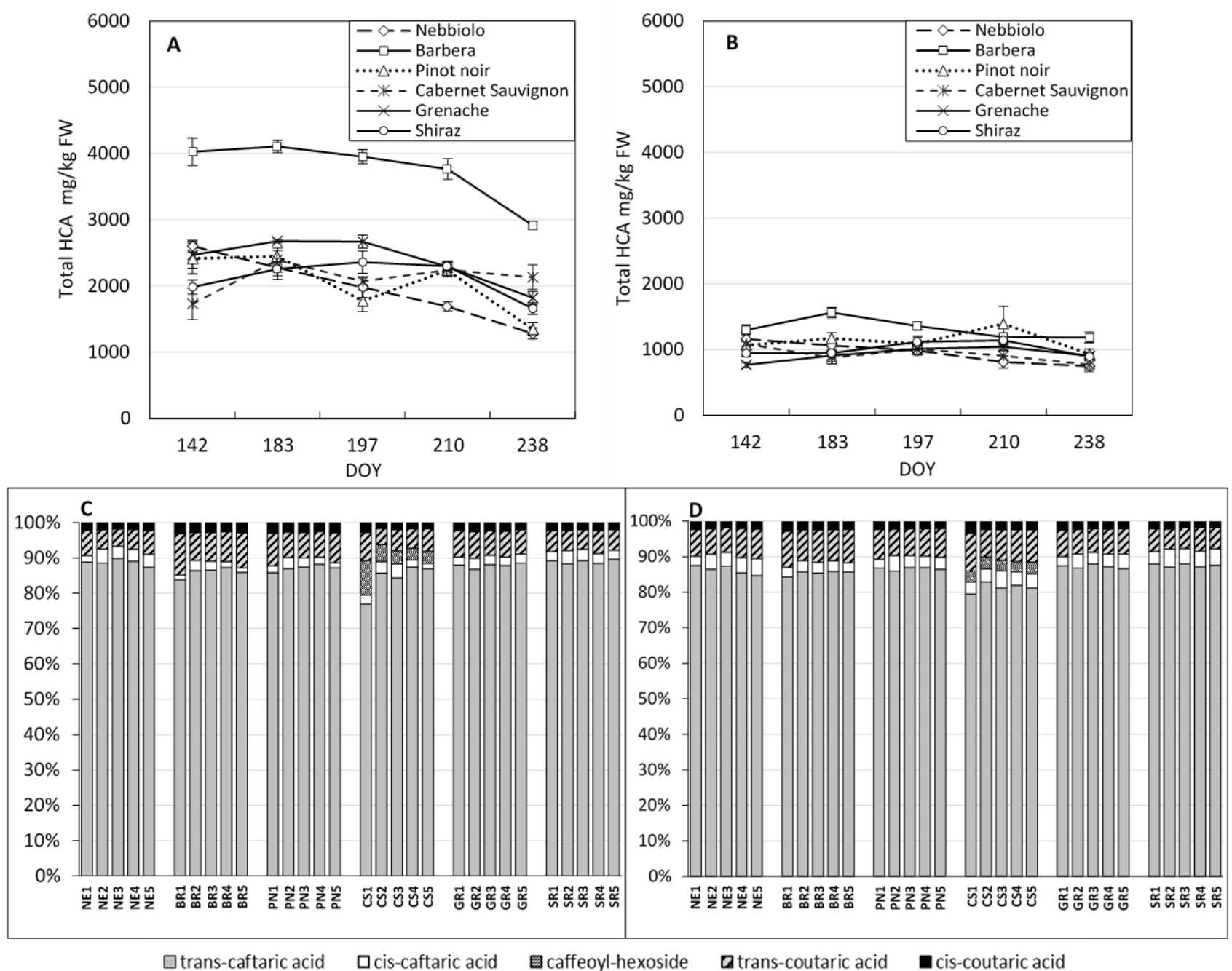

Figure 5 

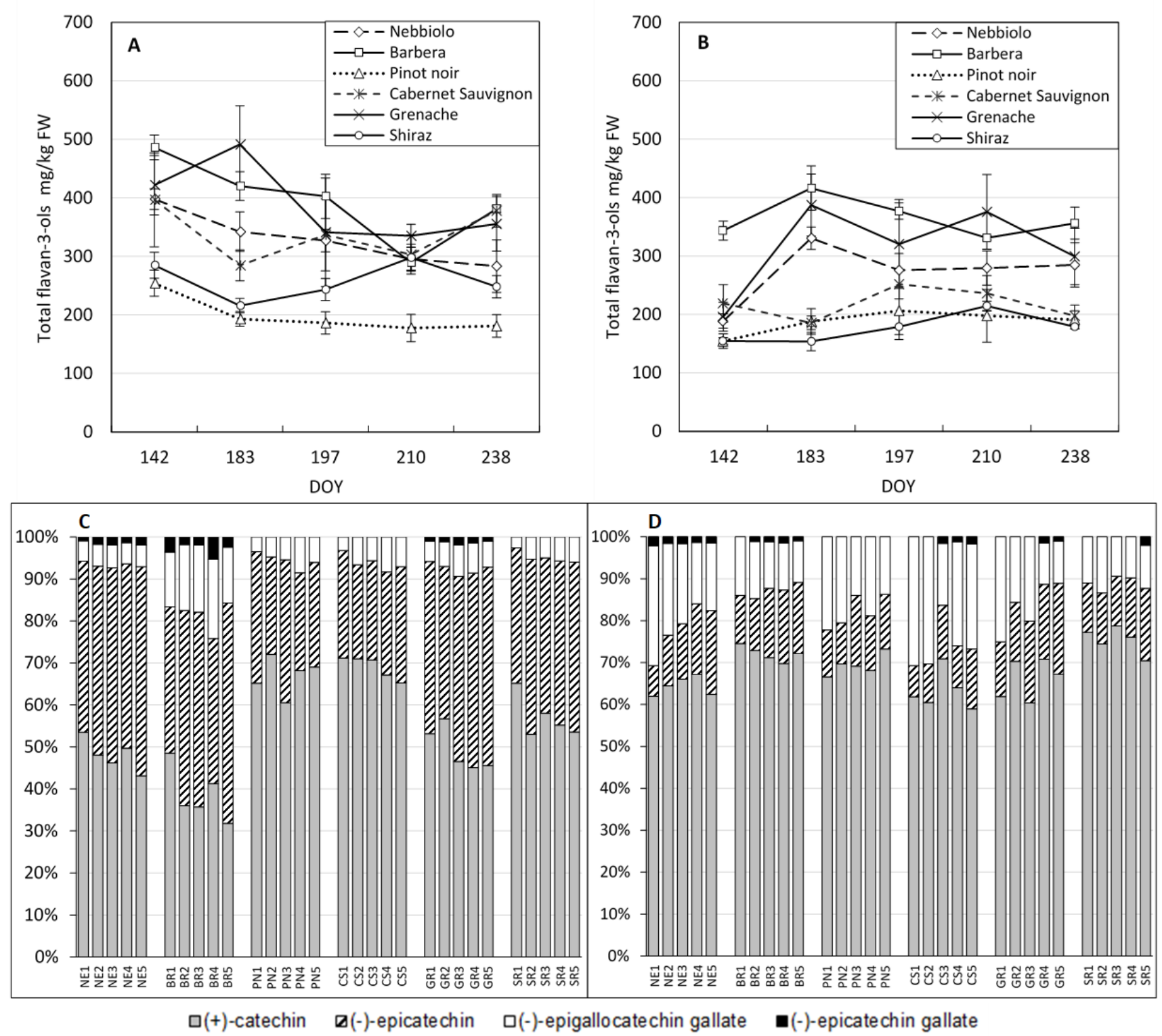

Figure 6 


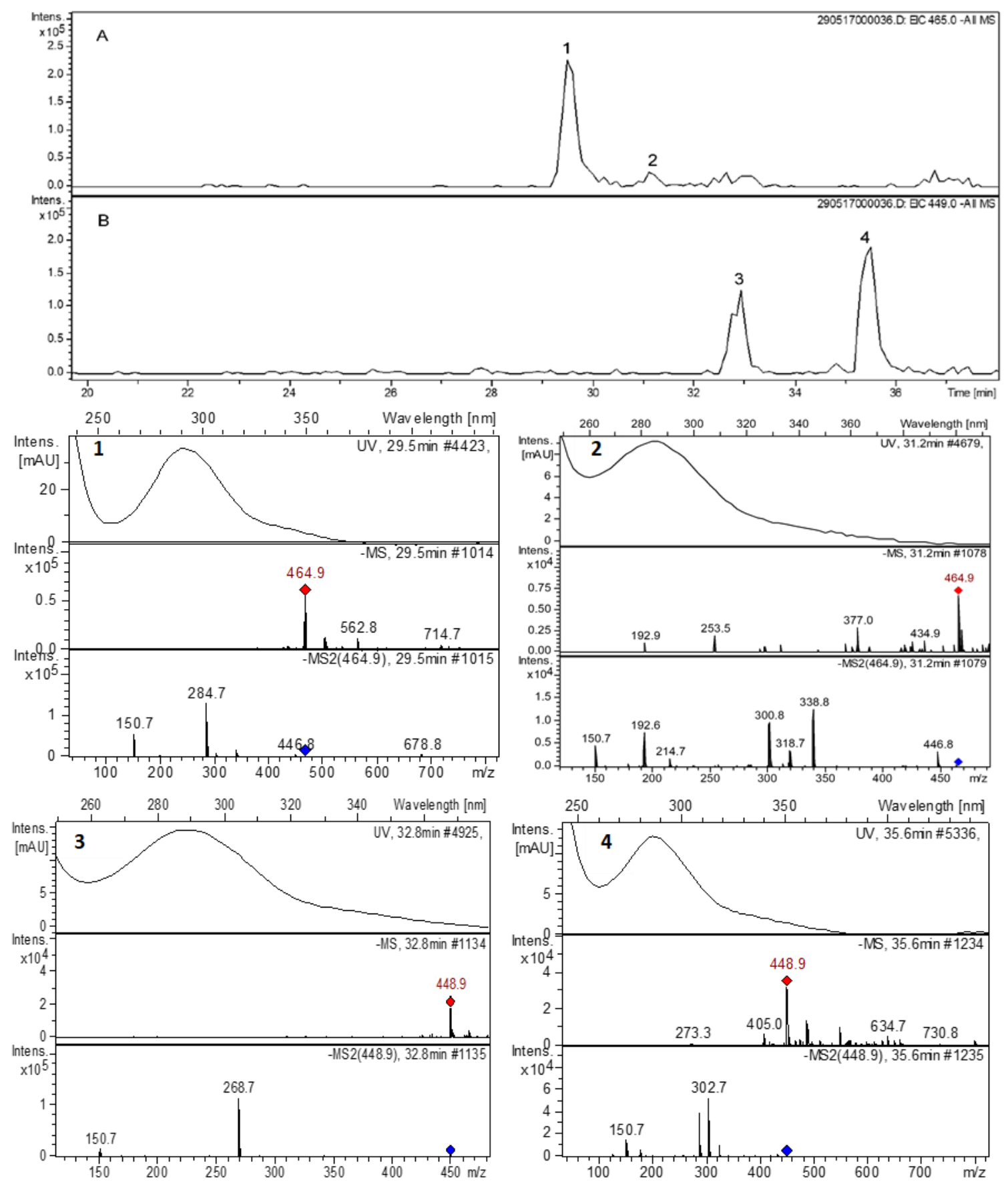

Figure 7 

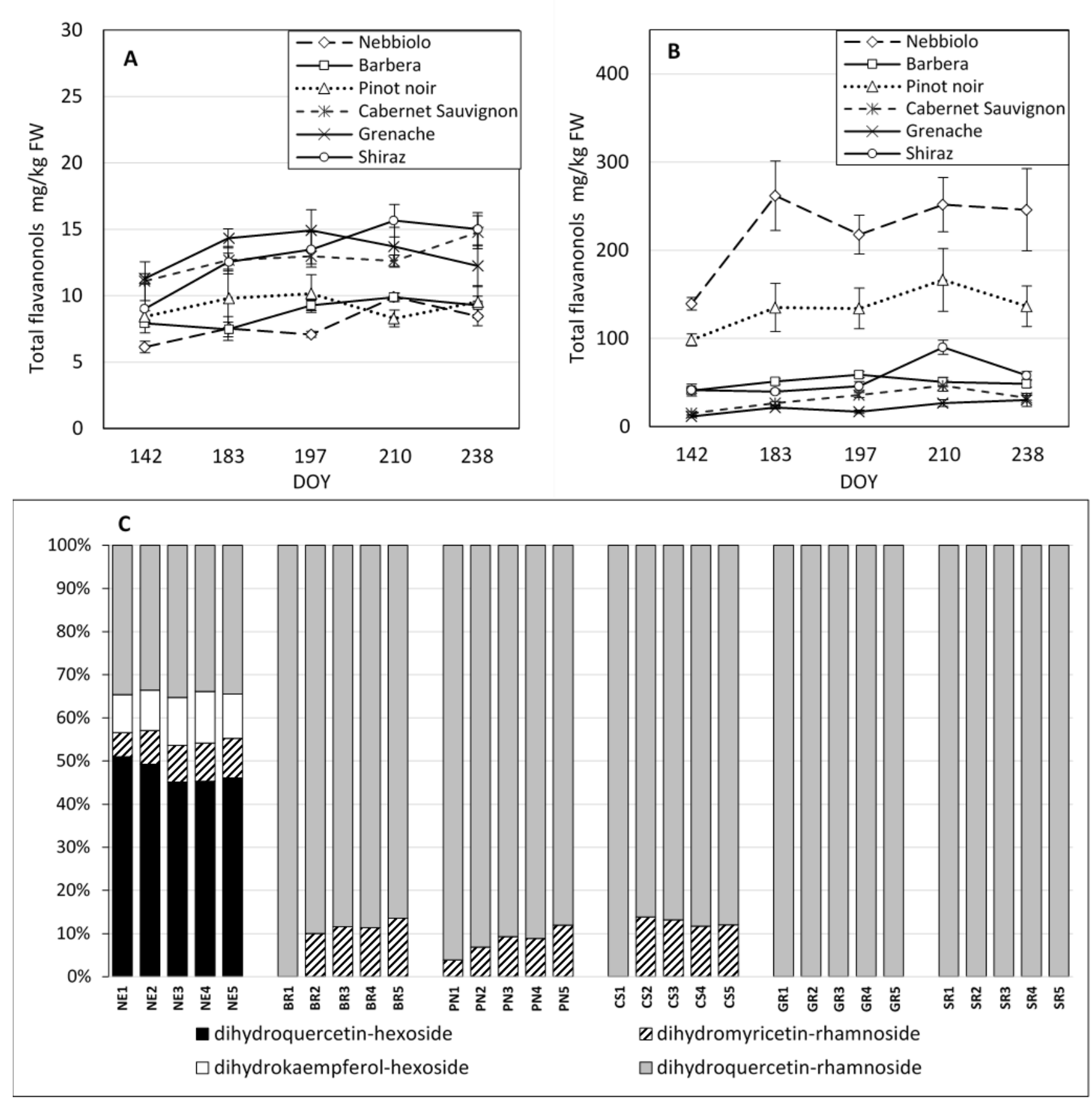

Figure 8 


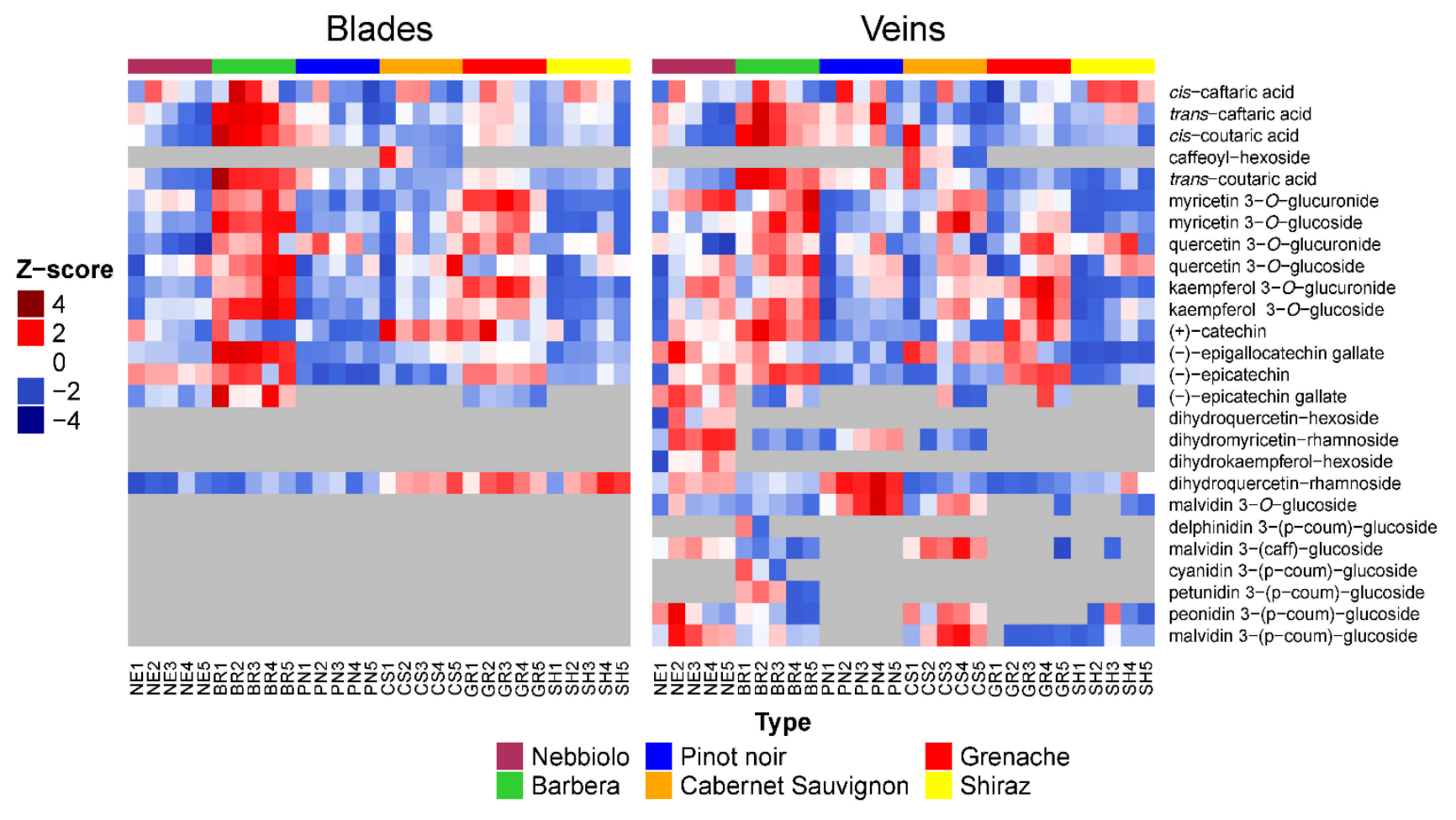

Figure 9 
$\underline{\text { TOC graphic }}$

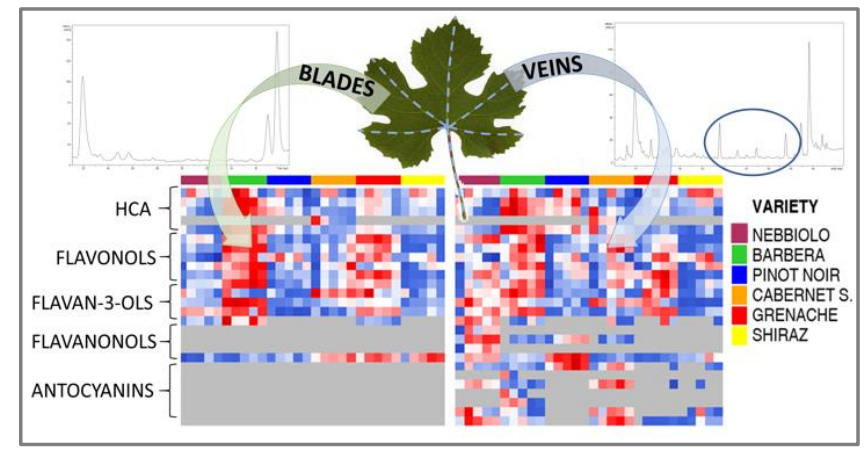

